\title{
Article \\ Does a Rise in Income Inequality Lead to Rises in Transportation Inequality and Mobility Practice Inequality?
}

\author{
Joko Purwanto \\ Transport \& Mobility Leuven, 3010 Leuven, Belgium; E-Mail: joko@tmleuven.be \\ Submitted: 20 October 2015 | Accepted: 3 February 2016 | Published: 7 June 2016
}

\begin{abstract}
Social and economic inequalities have sharpened in the late $20^{\text {th }}$ century. During this period, Europe has witnessed a rising unemployment rate, a declining wages for the least qualified workers, a slowing of income growth, and an increasing gap between the richest and the poorest. Based on the hypothesis of the relation between socio-economic condition and mobility behaviour, it is necessary to ask how these socio-economic inequalities manifest themselves in transportation: does a rise in income inequality lead to a rise in transportation inequality and mobility practice inequality? This question is particularly relevant today as some European countries are facing high socio-economic inequalities following the financial crisis that started in 2008. Using results from transport, car ownership and mobility surveys as well as household surveys from the Paris (Île-de-France) region between eighties and late nineties, this paper tries to answer this question. The results show how inequalities in transportation and mobility practice have decreased during the period in spite of an increase in income inequalities. We find that the evolution of socio-economic inequality, most specifically income inequality was simply one of the determining factors of the evolution of inequalities in transportation and mobility practice. In fact, the most important role in that evolution is not played by the evolution of income inequality but by the evolution of elasticity between transportation and income. Reducing the effects of this elasticity should be the main target of transport policies to diminish inequality in transportation and mobility practice.
\end{abstract}

\section{Keywords}

car ownership; income inequality; mobility practice; Paris region; social inequality; transportation; travel budget; travel costs; travel time; trips frequency

\section{Issue}

This article is part of the issue "Transport Policy and Social Inclusion", edited by Miriam Ricci, Graham Parkhurst and Juliet Jain (University of the West of England, UK).

(C) 2016 by the author; licensee Cogitatio (Lisbon, Portugal). This article is licensed under a Creative Commons Attribution 4.0 International License (CC BY).

\section{Introduction}

In the last 30 year period, Europe has witnessed an increase in economic and social inequality. These problems take several forms, for example, the growth of unemployment especially within the poorest population categories, the fall in real wages of the least qualified workers, the general deceleration in income growth, and the increasing income gap between the richest and the poorest. Piketty (2002) has found that inequality in the distribution of income per consumption unit in France has been constant since the eighties after having undergone a strong decrease during the previous decade. A weak trend of increasing inequality can, however be detected since the nineties. Based on this phenomenon, one can now ask if these inequalities in social and economic sectors have an impact on mobility. Can a relationship between them be explored?

In order to answer this question, this paper presents an analysis of the dynamic of inequality by using the method of concentration index decomposition developed by Podder (1993) and by Wagstaff, Van Doorlaer and Watanabe (2003). This method allows us, first, to analyse the contribution of each socio-economic and demographic factor to the inequalities in mobility in static terms: at a given point in time and, second, in dy- 
namic terms: between two points in time. Finally, this method helps analyse the impact of policies by separating out the effects on inequality of various changes.

This paper will first present three sources of data that concern the Paris region (L'île-de-France) of France to support this work. Subsequently, using the above three types of data we present an analysis of the economic inequalities of the Paris region followed by an exploration of the demographic and socioprofessional characteristics of the households. Finally, it will introduce the concentration index decomposition previously mentioned as the main method. This method application allows us to come to some conclusions as answers to the main question of this research.

The phenomenon of inequalities in mobility in its various forms, among others, the mobility characteristics of people coming from different socio-economic classes is in fact closely related to spatial segregation issues such as socio-spatial exclusion. In the context of the relationship between spatial segregation and inequalities in mobility, this paper helps prepare a framework of analysis for social exclusion from the starting point of mobility. More specifically, this paper shows the potential of using an econometrical methodology to describe the role of the different socio-economic factors that contribute to inequalities in mobility and its evolution.

\section{Data}

Having chosen the Paris region of France as a case study, the analysis was based on the results of three kinds of survey as explained in the following three subsections.

\subsection{Global Survey of Transport}

The first type of survey was the Enquêtes Globales de Transport or Global Survey of Transport of the years 1983, 1991 and 1997 (Direction Régionale et Interdépartementale de l'Équipement et de l'Aménagement, 1983, 1991, 1997). Abbreviated as EGT, it is a background survey on trips of people living in the Paris region (Îlede-France) which includes most of the basic themes of a mobility survey: number of trips, choice of mode, types of connections, patterns, lengths, travelling speed, and time budget. 10027 households (23601 individuals and 80181 trips) were surveyed in 1983, 11291 households (26009 individuals and 91243 trips) in 1991, and 4285 households (9681 individuals and 35907 trips) in 1997 . The survey questionnaire focuses on three types of information concerning the interviewee's trips during one particular working day, the day prior to the interview, outside the holiday season: the general characteristics of the household, the characteristics of people aged more than 5 years old, and the trips of persons.
In this survey, each household was required to indicate their total annual household income, including: bonuses, the " $13^{\text {th }}$ month" salary, all other secondary activity income, all income related to movable and non-movable property, social benefits and so on. The definition of income in this survey is not elaborated upon, i.e. interviewees had the liberty to interpret it. No deduction due to direct taxes is taken into account in this income definition. Each household interviewed was required to answer this question by selecting one of the annual household income classes. 1983 survey consists of 13 income classes while that of 1991 and 1997 consist of 10 classes.

Two problems have been detected in relation to income information of EGT.

The first problem concerns the use of per household income as the living standard indicator.

Income per household information might give some idea of how much a household disposes in term of financial resource; however this information is a poor indicator of living standards. For example the standard of living in a household composed by a single person earning a monthly wage of $€ 3,000$ is not equal to the living standard of a household with three or four children whose parents earn the same monthly income as the previous household. To obtain a better living standard indicator, we need to take into account at least two additional aspects, household size and composition, for example by calculating the household average income per consumption unit. Unfortunately the information available in EGT does not allow us to calculate the consumption unit value per household as in this survey we cannot distinguish the age of each household's member. The best that we could do in this case was to calculate the average income per capita of the household.

For this work the average per capita income of the household is calculated by assigning the average per household income value of each class to every household belonging to that class and then dividing this value by the household size. Once the income data has been reordered in function of per capita income classes it is possible to see that this distribution had too many biases, for example through checking on the per household and per capita car ownership level in function of their income. The Appendix 1 shows an example of these biases based on 1997 EGT result.

In spite of some fluctuations, Appendix 1 shows that per household and per capita car ownership levels have increased in general with the household income level. This relationship becomes erroneous when trying to represent these car ownership levels in function of per capita income. In Appendix 1 it can be seen that the per household and per capita car ownership level of the $6^{\text {th }}$ decile households are lower than those of the other deciles. This has to do with the high percentage of single person households that belong to the $6^{\text {th }}$ decile. 
To cope with this problem, the method used in Claisse et al. (2000) has been adopted and assigned to each household a theoretical and random value of income within the concerned income class. First, it is necessary to determine the percentage of households found theoretically below and above of the central (income) value of the concerned income class. This percentage is calculated in function of the slope of the cumulated distribution curve of the household population according to their income. An example of the estimated percentages for 1997 EGT is given in the Appendix 2.

The second problem detected was that of nonresponse.

The non-response percentages on the income question were respectively $11.7 \%, 11.4 \%$ and $9.8 \%$ for 1983 , 1991 and 1997 EGT. These non-response households did not fundamentally correspond to any category representing homogenous characteristics. However, it was found that the majority of these households (52\%) were families whose heads were older than 50 years old (against $39 \%$ of the households that have answered the income question). $30 \%$ of these non-response households had retired heads (against the average of $22 \%$ ) and $45 \%$ of these non-response households had non-active heads (against the average of 34\%).

To deal with this non-response problem, we used one of imputation of missing-data methods proposed by Richardson \& Loeis (1997) and Armoogum \& Madre (1997). Imputation of missing-data are methods of dealing with item non-response by imputing (estimating) values for the missing data based on some other source of information. Among these imputation methods is the "class mean imputation". Based on this method we first divided the sample population into strata based on other variables in the dataset, and then calculated the mean of the variable to be imputed within each strata. More precisely, we divided the households having replied the income question based on their car ownership level. In each car ownership level class, we calculated the average per capita income by distinguishing the households composed by only one person. The objective was to take into account the household structure effect in order to get a better homogeneity between the households found in the same class of car ownership. We finally imputed the average income per person for the non-response households as a function of their car ownership level.

\subsection{INSEE Household Budget Survey (BDF)}

The second type of survey was the Enquêtes Budget de Famille or the Household Budget Survey of the French National Institute of Statistics and Economic Studies (INSEE). Abbreviated as BDF, INSEE conducts this survey every 5 years and covers households living in France. For the purpose of this research it has only tak- en an extract of data consisting of households living in the Paris region or francilien household. The amount of these franciliens households covered in the survey are 1999, 2180, 1455 and 1706 respectively for the survey years of 1979, 1984, 1989 and 1994.

The main objective of this survey is to analyse the expense and the income resources of the observed households in order to allow comparisons between the different living standards and consumption choices of the different household categories. The main information gathered in the BDF is the nature and totality of households' expenditure, consumption and income resources. In this research, only some descriptive information of the households such as family composition, education level, type of employment of each family member as well as their mobility characteristics and budget have been used.

BDF has income information in terms of total annual household income. As opposed to EGT, BDF interviewees are asked to give their income information precisely instead of selecting a class of income. The interviewed households provide this information for each of the 73 household income types. These 73 types are grouped into three main categories: activity income, social benefits and capital income. Activity income is the sum of all salary including those of independent (liberal profession) income and income coming from secondary activities. Social benefits include retirement benefits, unemployment benefits, scholarships, familial social benefits, housing subsidies, subsidies or financial support in relation to invalidity, to specific family composition, other social benefits and the RMI or the Revenu minimum d'insertion which is a French form of social benefits aimed at people without any income who are of working age but do not have any other rights to unemployment benefits. Capital income is the sum of all income coming from tradable financial assets or securities and all income coming from real-estate assets. The sum of these three main income categories is the total annual household income. It is possible to consider this total yearly household income the household net income after obligatory tax deduction at source. However, direct taxes such as income, property and housing taxes are not yet excluded. The definition of household income in BDF is relatively comparable then to the one of the EGT.

Having income information declared specifically (rather than in income classes) allows us to proceed directly to living standard measures. In this work we present data from BDF not only in its original unit (per household income) but also in more living standard related measures, namely per person income and per consumption unit income. The latter is possible as we find household information in BDF not only in terms of size but also in terms of structure, such as the age of each household member.

We used the Eurostat consumption unit scale to 
calculate per consumption unit income. This scale gives weight of 1 (one) to the household head (or the first adult member of the household), weight of 0.5 to each of the remaining adult members and 0.3 to each of the child members. Adult members are all persons of 14 year-old and older living in the household. This choice of scale is made solely on the base of comparability. INSEE and Organisation for Economic Co-operation and Development or OECD also use the Eurostat scale for their work.

\subsection{INSEE Parc Auto Surveys}

The last type of survey was the Enquête INSEE de conjoncture auprès des ménages or INSEE's households situation survey between 1972 and 1994 followed by the Panel Parc-Auto or Car Fleet Panel Survey conducted between 1994 and 1998 by three French institutes INRETS, ADEME and SOFRES.

In this survey and panel, household income is declared in 12 classes. We have implemented an imputation method upon these 12 classes in order to obtain 4 quartiles of household income and per consumption unit income. This particular imputation method consists of interpolating the distribution of a variable of interest, i.e. car ownership level per household, in order to define the limit between each income quartile and calculating the average car ownership level in each quartile. Here we made the rather strong assumption that within each income quartile, the household car ownership level did not vary in function of income.

The use of this simple method which is based on the interpolation of income class distribution can be generalized without problem to all orders of quantiles (tertile, quintiles, decile, etc.) under the condition that the number of original classes always be higher than the number of quantiles. Madre \& Purwanto (2003) show the application and validation of this method by using as a case study a sample of households that have declared their total income (in number) in the INSEEINRETS National Survey of Transport and Communication (I'Enquête Nationale INSEE-INRETS Transports et Communications de) 1993-1994.

\section{Economic Inequalities in Paris Region}

The Île-de France or Paris region is the region with the highest living standard in comparison to the other French regions. According to the Institut National de la Statistique et des Études Économiques (1998), the living standard level of Paris region is on average twice that of French overseas departments and 1.4 times of that of the other French departments' altogether.

However, in the interior of the region that can be divided into three concentric geographical zones, i.e. municipality of Paris or Intramural Paris, Petite Couronne (the Inner Circle) and Grande Couronne (the
Outer Circle), the inequality in income distribution is quite strong. Appendix 3 shows how, between its three concentric geographical zones, Paris is the zone with the lowest average per household income. However as Intramural Paris households are composed by strong proportion of single person families, the living standard of the zone, calculated in term of per-unit consumption income, is the highest in the region. Households living in the Outer Circle, the zone with the weakest urbanization level in the region, have the lowest living standard.

The Institut National de la Statistique et des Études Économiques (1998) also remarks that the average per consumption unit income in France increased by an average of $4 \%$ per year during the seventies followed by a growth deceleration during the eighties when annual growth was merely $0.85 \%$. The living standard growth remained constant between 1990 and 1996.

During the same period, the Paris region had a different evolutionary curve: based on calculations using BDF data as shown in the Appendix 3 the region underwent a period of stagnation or slight drop of per consumption unit between 1979 and 1989 followed by a rise between 1989 and 1994. It can also be observed that the per-household income grew less than the per person income during the whole observed period. This phenomenon was caused by a significant drop of the household size in all zones during the same period as shown in the Appendix 4.

Observing imputation method calculation results of EGT (Appendix 5), we see an increase in both levels of income, i.e. per household and per person income in Paris region between 1983 and 1991 followed by a weak drop or stagnation between 1991 and 1997.

At first sight, income data shown by two different data sources appears to have different evolution curves. In order to understand this one should remember that the income structures in the two surveys are not the same. The average incomes calculated from BDF are generally lower than those calculated from EGT. It is not easy to track down the evolution of the household income between 1979 and 1997, for example, using these two sources.

\subsection{Income Distribution Analysis Based on Three Sources of Data}

According to Piketty (2002) inequality of income per consumption unit in France was in stagnation in the eighties, after undergoing a sharp drop in the seventies. Still according to him, a slight rising trend can be detected since the beginning of nineties and this dynamic evolution of income distribution inequality in France was consistent with the trends experienced by all Western countries: income inequality especially in wage stopped falling in the eighties and nineties.

Moreover, the Institut National de la Statistique et des Études Économiques (1998) finds that income ine- 
quality today between 1990 and 1996 increasingly affected young families. Income continued to rise for older age groups while it stopped growing for younger age groups: households with a family head age between 25-35 years had the same income per consumption unit (in constant currency) as the same category ten or twenty years earlier.

Are these phenomena seen over the same period in the Île-de-France (Paris region)?

In the following paragraphs we will see an analysis of the Paris region using three different sources of information: EGT, BDF, and INSEE Parc Auto.

First, the analysis based on three comprehensive surveys of transport (EGT) shows that there was a significant increase in inequality of household income distribution between 1983 and the nineties (1991 and 1997).

The increase in household total income distribution and per person income distribution inequality was confirmed by calculating Gini coefficients. We see that changes in Gini coefficients (Appendix 6) and 10th/1st decile ratios (Appendix 7) between 1983 and 1991 in the Paris region as well as in its three geographical subregions were more significant compared to those coefficients and ratios from the 1991-1997 period. Inequalities of household income distribution increased more during the 1983-1991 period than during the following period. The same evolutionary trends are found in inequalities in terms of per person income distribution as shown in the Appendix 8 and the Appendix 9.

It is noticeable that income distribution inequalities among Parisian households were always higher than those between peri-urban households, i.e. households within the Inner and Outer Circle of the region.

The analysis from the four BDF surveys confirmed how inequalities in household income distribution among Parisians are greater than those that occur among peri-urban households. The results of these surveys also confirm that inequalities among the Outer Circle households are the lowest in the region (see Appendix 10 to Appendix 15).

There is no observable singular and clear trend of inequality evolution in Paris region between 1979 and 1994 from Gini coefficient and $10^{\text {th }} / 1^{\text {st }}$ decile ratio appendix above, that has been calculated using BDF results. It is also possible to see a slight inversing trend on per-person and per-consumption unit income distribution: while Gini coefficients of the total household income distribution (Appendix 12) and the per-unit consumption income distribution (Appendix 14) in the whole Paris region (see Île-de-France columns) and in the Inner Circle were decreasing between 1979 and 1984 , the $10^{\text {th }} / 1^{\text {st }}$ ratios were increasing, as shown in the Appendix 13 for per person income distribution and the Appendix 15 for per-unit consumption income distribution. This shows how the inequality in general might decrease at the same time as the disparity between the richest and the poorest grows larger.
One significant finding from those Appendices is the trend that inequality in income distribution at all levels (namely, household, per capita and per consumption unit) in Intramural Paris increased between 1989 and 1994 as shown by the two inequality indicators, i.e. Gini coefficients and $10^{\text {th }} / 1^{\text {st }}$ ratios. In the two other regions, the inequality indicators show rather stagnation and even slight decrease of income inequalities.

Finally, analysis of inequalities in household income distribution by applying the interquartile ratio $\left(4^{\text {th }} / 1^{\text {st }}\right)$ based on the Parc Auto Survey data shows three things. First, the $4^{\text {th }} / 1^{\text {st }}$ ratios were in general lower for the 1980 's relative to the 1970 's, second, that the ratios were stagnant between the second half of the 1980 's and the first half of the 1990's, and third, that starting from 1995, the magnitude of the ratios returned to the levels seen at the end of the 1970's (see the Appendix 16).

A calculation done using the same ratio based on household surveys (BDF) confirms these results and reconfirms that inequalities in household income distribution were the strongest among central Parisian households and the weakest among the households living in the outer circle area (Appendix 17).

In general, we can confirm a trend of reducing inequalities in income distribution among households in the Paris region from the seventies to the eighties, stagnation during the eighties, followed by an increase from the eighties to the nineties especially in Intramural Paris.

\subsection{Demographical and Socio-Professional Characteristics of the Households}

Elderly households, namely households with head of the family being 66 years old or more, composed the majority of the first decile in the distribution of income per consumption unit. The Appendix 18 however, shows a significant drop in the share percentage of these elderly households in the $1^{\text {st }}$ decile from the first survey in 1979 (44\%) to the forth survey in 1994 (13\%). During the same period, we see an increasing percentage of younger households in this lowest income group, particularly those with heads under 25 . This rejuvenation of the poorest households can imply the existence of two factors: employment or wage inequality that touches mostly younger people and the extension the study period. The Institut National de la Statistique et des Études Économiques (1998) shows this: the age at which more than $50 \%$ of young people had stable employment is 25 years ( 23.5 years in 1970 ), while the median age of school leavers was 21 years (20.5 years in 1990).

Regarding inequality in employment, Chauvel (1998) finds that during the 1990's in France, when the unemployment rate reached $13 \%$ of the working population, $25 \%$ of active people under 24 years old were 
unemployed. Wage inequality in France has worsened since 1975: while wages for older people continued to increase, wages of hiring younger people steadily declined. In 1995 the average living standard of households with heads aged between 50 and 59 years old was $40 \%$ higher than those with heads of 30 years old while in 1975 it was only 10-15\% (Baudelot \& Establet, 2000).

Younger families, in particular those whose head was aged younger than 31 , were very poorly represented among the wealthiest households ( $10^{\text {th }}$ decile). An increase in the proportion of very elderly households ( $\geq 66$ ) in this decile was visible between 1979 and 1994.

We conclude that in Île-de-France there was a rejuvenation of the poorest households and an aging of the wealthiest households. The Institut national de la statistique et des études économiques (1998), moreover, finds that this aging was due to two factors: the increase in the average income of all pensioners and progression of capital income or heritage towards end-of-life.

The increase in average income for all pensioners' resulted solely from generational replacement, for example, a household with a 60 year-old head at a given date, had an average per consumption unit income higher than a household with the head of family of the same age at an earlier date. From one period in time to another, we are no longer in the presence of the same people. In 1996, people reaching retirement age may have benefited from more favourable retirement regulations, and often belonged to couples receiving two pensions.

Regarding socio-professional category, Appendix 19 shows a significant decrease in the percentage of retired households among households of the $1^{\text {st }}$ decile 1984 (37\%) to 1994 (15\%) which was consistent with the results of Appendix 18. In 1984, 37\% of households in the $1^{\text {st }}$ decile were households with retired heads, whereas in 1994, $47 \%$ were households of with employees and/or workers at their heads. What can be seen is that these last two categories of actives were the most disadvantaged professional categories. Yet the total percentage of workers in the lle-de-France experienced a real decline since the early 1980's.

Despite the $30 \%$ increase of the minimum wage in 1968, according to Piketty (2002), France was the country with the highest wage inequality in the western world in 1970, this inequality decreased rapidly during the seventies and then stabilized during the eighties and nineties, with a very small increase from 1983 to 1984 . Piketty suggests, this stability was due primarily to the ongoing differences in the level of education and qualifications which explains the permanence of wage gaps. While the least skilled wage passed the certificate of study in brevet, the most qualified employees also lengthened the duration of their studies, attaining diplomas of higher education. The whole hierarchy of qualifications and wages moved up without notable change in difference. Secondly, this stability seems due to social perceptions that likely play a role in wage hierarchies. What a society considers a "fair" inequality probably contributes to the inertia of this wage inequality (see Jardin, 2003).

Over half of households in the $10^{\text {th }}$ decile belonged to executives and liberal professions. The percentage of retired person households was rather important among this richest group that increased from $19 \%$ in 1984 to $23 \%$ in 1994 . On the other hand, the proportion of retired households in the $1^{\text {st }}$ decile of households experienced a significant drop from $37 \%$ in 1984 to $15 \%$ in 1994 . Fournier (2003) finds that these retirees were mostly those people who have received the best share of the cake at the end of their working life. Although strong inequalities existed within this category, the revaluation of pensions made in the 1980's led to a revenue increase of senior citizens at the same time when the active youth incomes stalled.

Finally, Appendix 20 shows that the $1^{\text {st }}$ decile of per consumption unit income were composed of households consisting of first singles, then unemployed, large and single parent households. Between 1979 and 1994, we find that the share of single households among first decile households decreased while it also increased in the $10^{\text {th }}$ decile. In contrary, the share of 'unemployed' households among the poorest households doubled during the same period which is consistent with the phenomenon of inequality in employment.

\section{Concentration Index Decomposition}

The basis of the method is linked to the need to incorporate the analysis of mobility distribution to the econometrical framework through a simplified model of mobility. In principle, this analytical work requires a twofold approach.

First, the identification of sources of mobility inequalities is based on a formulation of concentration index as an indicator of its determinants. Assuming that during a given period, the relation between a mobility indicator $y$ of a person $i$ and a set of $k$ individual factors $x_{k}$ is represented by the following linear equation:

$$
y_{i}=\alpha+\sum_{k} \beta_{k} x_{k i}+\varepsilon_{i}
$$

where $B_{k}$ are the coefficients and $\varepsilon_{i}$ is the random term. When equation (1) has significant relationship, it can be used to decompose the socio-economic cause of inequality in mobility.

Wagstaff, et al. (2003) show that based on the relationship estimated in equation (1), the concentration index $C$ of the variable $y$ can be written as

$$
C=\sum_{k}\left(\beta_{k} \bar{x}_{k} / \mu\right) C_{k}+G C_{\varepsilon} / \mu
$$


where $\mu$ is the average of $y, x_{k}$ is the average of $x_{k}$, and $C_{k}$ is the concentration index of $x_{k}$. Residual or $G C_{\varepsilon}$ (generalized concentration index for the error term) is defined in the last part of equation (2) as:

$G C_{\varepsilon}=\frac{2}{n} \sum_{i=1}^{n} \varepsilon_{i} R_{i}$

with $n$ being the total number of population segments and $R_{i}$ being fractional rank of the ith person in the income distribution. Equations (1) and (2) show how the concentration index $C$ is in fact composed of two elements, the deterministic and the residual. The first element is the deterministic element, equal to the weighted sum of the concentration index relative to regressors $k$. The weight is simply the elasticity of $y$ with respect to $x_{k}$, calculated at the sample average. The second element is the residual element that represents the mobility inequalities not captured by the factors $x_{k}$.

Secondly, where data allows, it is important to understand the causes of changes in mobility inequalities over time. Several approaches can be used for this purpose. The simplest option consists of evaluating the discrepancy between inequalities in two different points in time assuming that all components of social, economic and demographic inequalities are changing.

$\Delta C=\sum_{k}\left(\beta_{k t} \bar{x}_{k t} / \mu_{t}\right) C_{k t}-\sum_{k}\left(\beta_{k t-1} \bar{x}_{k t-1} / \mu_{t-1}\right) C_{k t-1}+\Delta\left(G C_{k t} / \mu_{t}\right)$

However, this approach does not allow one to specify if variation in the inequality of mobility $\Delta C$ is due to change in inequalities (concentration index) of its determining factors, $C_{k}$, or if it is due to change of other influences $-b_{k}$ and $x_{k}$. For this reason, a decomposition of mobility inequality using the method developed by Oaxaca (1973) appears to be slightly more fruitful. Assuming $\eta_{k t}$ as the elasticity of $y$ with respect to $x$ at time $t$, the decomposition structure of Oaxaca can be written as follows:

$\Delta C=\sum_{k} \eta_{k t}\left(C_{k t}-C_{k t-1}\right)+\sum_{k} C_{k t-1}\left(\eta_{k t}-\eta_{k t-1}\right)+\Delta\left(G C_{t t} / \mu_{t}\right)$

or

$\Delta C=\sum_{k} \eta_{k t-1}\left(C_{k t}-C_{k t-1}\right)+\sum_{k} C_{k t}\left(\eta_{k t}-\eta_{k t-1}\right)+\Delta\left(G C_{g t} / \mu_{t}\right)$

or according to Lachaud (2003):

$\Delta C=\sum_{k} 0,5\left(\eta_{k t}+\eta_{k-1}\right)\left(C_{k t}-C_{k t-1}\right)+\sum_{k} 0,5\left(C_{k t}+C_{k t-1}\right)\left(\eta_{k t}-\eta_{k-1}\right)+\Delta\left(G C_{t t} / \mu_{t}\right)$

Equations (5) to (7) allow tracing the double sources of variation in mobility inequality: (i) variations of inequality of the determining factors of mobility and (ii) varia- tions of elasticity of the determining factors. It is worth noting that the method of decomposition proposed by these equations weights the variation of inequalities by the average of elasticities and the variation of elasticities by the average of inequalities (concentration indexes).

\section{Inequalities in Transport and Mobility}

In equation (1), $y_{i}$, the dependent variable measures of mobility. Ten indicators of mobility are considered:

- Number of trips per day per person (all modes)

- Number of trips by car per day per person

- Number of trips by public transit per day per person

- Number of trips on foot per day per person

- Distance travelled (km) per day per person (all modes)

- Distance travelled $(\mathrm{km})$ by car per day per person

- Distance travelled $(\mathrm{km})$ by public transit per day per person

- Average speed $(\mathrm{km} / \mathrm{h})$ per day per person (all modes)

- Average speed $(\mathrm{km} / \mathrm{h})$ by car per day per person

- Average speed $(\mathrm{km} / \mathrm{h})$ by public transit per day per person

To explain variations of these mobility variables, we adopt a classic model of trip generation. This model explains the number of trips produced per household by using several explanatory variables. According to McNally (2000), these variables are: the car ownership level of the household, household income, household size, the number of actives per household, etc. We have generalized this model by converting it to the "individual" level and by using it to estimate other indicators of mobility.

We retain several explanatory variables as follows:

- age and the square of age

- average income per person in the household

- social professional category of each individual: active (worker), retired, unemployed, student, and staying at home (inactive) where male and female are distinguished in each type

- dwelling zones in Paris region: Intramural Paris or Paris Inner circle and Outer circle

The independent variable of "age" does not enter the equation linearly. This allows one to incorporate the effect that mobility increase with age up to a certain point and then gradually drops.

The average income per person represents the living standard of the household in which the person belongs to. We used the inactive individual ("F-at home") as the referenced social professional category and the 
Outer Circle ("F-Outer Circle") as the referenced dwelling zone.

These independent variables do not fully explain the variation in mobility as given in Appendix 21 to Appendix 23. The coefficients of determination $R^{2}$ were relatively low, especially for the frequency of trips and walking. The regression results are summarized in the following paragraph.

First, mobility indicators depended directly on the age of individuals. Coefficients on age are almost all positive. In fact, except for walking related indicators, the age squared was significantly involved in a negative way. Secondly, contrary to popular belief, per capita income played a small role. This was indicated by the values of estimated coefficients that were low compared to other coefficients of variables. However, these coefficients were generally positive. Third, the coefficients of the number of cars per person are generally highest in absolute terms compared to those of other variables. Except in frequency and distance in public transport and in frequency of walking, these values were always positive. Fourth, being a professionally active man actually promotes mobility by car. This was indicated by the high positive values of the coefficients in this category for frequency, distance and travel speed by car. Being a professionally active woman or a student promoted mobility by public transit. Housewives and other non-active categories show positive strong coefficients in walking frequency. Fifth, living in the Outer Circle seemed to be a factor that boosted mobility, in particular in terms of distance and speed. We find the opposite characteristics of living in Intramural Paris, which boosted trip frequency in public transit and walking. Living in the Inner Circle was always found between these two extremes.

Before analysing the decomposition of inequalities of the different mobility indicators, it is important to look at the indicator of inequalities that we used. In this analysis, it is the concentration index or concentration coefficient of mobility in comparison to individual income distribution. Inequality is then measured by a variable, in this case the mobility indicators, which is distributed between the different persons ranked according to their individual income. We observe then for example, if this variable of mobility is more concentrated among individuals with low income or among individuals with high income or if it is distributed proportionally according to the individual income.

Appendix 24 shows the concentration index of several mobility indicators. The positive values of these indexes suggests in most of the indicators that these variables were more concentrated among the individuals with high income. The higher the index value, the more concentrated this variable was among "rich" people and the inequality was more pronounced. On the contrary, negative values, which is found in the indicator of the "number of trips on foot per day per person" means that this variable was concentrated more among the individuals with low incomes.

In observing the fluctuation of these coefficients in time, it can be seen that most of these values were decreasing inversely to the trend of increasing inequality in the distribution of income per capita. The latter has been calculated in term of Gini index of the income per person distribution which grew from 0.315 in 1983 to 0.359 in 1991 and finally to 0.360 in 1997.

Does the fact that mobility indicators become in general less concentrated amongst wealthier people, necessarily mean that inequality of mobility has decreased during the observed period?

The answer to this question is rather difficult. For example, the decreasing concentration of trip frequency per day, by any modes, amongst the rich means that low income people have been moving with increasing frequency. On one hand, this might mean reduction in mobility inequality as we can interpret this as an increase in the mobility capacity of low income people but on the other hand, it might mean that low income people are "obliged" to make more frequent trips per day in order to fulfil their needs. The same also applies to other variables such as the distance travelled, by any mode, i.e. long distance travel might suggest freedom for some people but at the same time this might mean burden as low income people which are forced to live in the outskirts, far from their places of work or study. Finally the average speed might be the only indicator where a reduction of concentration among the rich people is always positive.

The aim of this research is, however, not to make a normative judgment on which level a concentration index of particular mobility indicators is fair or unfair. The aim is to discover how the different determining factors influence the final value of the concentration index.

\section{The Role of the Evolution of Socio-Economic Inequalities on Transportation and Mobility Practice Inequalities}

Detailed results of the decomposition method application, in relation to the equations (1) to (4) are given in Appendix 25 to Appendix 27. The Appendices show that inequality in the distribution of per capita income and per capita car ownership were the two main factors that explained the cause of inequalities in mobility at a particular point in time. For example, as shown in the Appendix 26, the inequalities of the income per person distribution explained $44 \%, 29 \%$, and $38 \%$ of the cause of inequalities in travelled distance distribution of all modes respectively for the year 1983, 1991, and 1997. Inequality in the distribution per capita of car ownership was in fact the factor that explained most the causes of inequalities in the distribution of three variables, namely, travelling speed (Appendix 
27), trip frequency by car (Appendix 25) and travelled distance by car (Appendix 26). It is interesting to note that this factor explained most of the causes of inequalities in the distribution of trip frequency on foot ( $57 \%, 48 \%$, and $48 \%$ for the three observed years) as shown in Appendix 25, in other words, the more private cars were concentrated among the high income people, the more low-income people walk.

In Appendix 26 we see how in the previous example inequalities in per capita income, per capita car ownership and socio-professional category, reinforced the concentration of the travelled distance by private cars among high income people. Inequalities in car ownership show negative values of contribution to the distribution of trip frequency (Appendix 25) and distance travelled (Appendix 26) in public transport. This means the more concentrated among rich people car ownership was, the less rich people used public transit.

Inequality in age distribution contributed positively to mobility inequalities, meaning that the tendency that older people were richer than younger people contributed to the concentration of more mobility towards the rich (or, in case of frequency of travelling on foot, towards the low income people).

Finally, except for the trip frequency in all modes and in public transit, inequality in the distribution of geographical area of the household contributed negatively to the mobility inequalities. This means that the trend where rich people lived more in Intramural Paris than in the Inner and Outer Circles weakened the concentration of mobility among the rich.

One problem has been found in relation to the residuals that for some mobility indicators were high, such as in the case of trip frequency per day by public transit (1991 and 1997), travelled distance per day by public transit $(1991,1997)$ and average travel speed by car and public transit (all observed years). These high residuals mean that the independent variables used were not sufficient to explain the concerned dependent mobility indicator variables.

Transversal analysis above reveals elements that constitute inequalities of mobility at a given point in time. In fact, the main objective of the use of this decomposition method is found in its dynamic analysis between two points in time. Results of this dynamic analysis are given in the following Appendices.

Between 1983 and 1991, it can be seen that inequalities decreased for all mobility indicators as shown by the Appendix 24. An explanation for this decrease can be found again in the evolution of two factors: income and car ownership level.

First, it was noticed that the evolution of inequality in the distribution of car ownership during this period largely determined the evolution of inequalities in the distribution of travel speed and trip frequency by car. The evolution of this factor was responsible also for $105 \%$ of the reduction in inequalities in the trip fre- quency by car (Appendix 28). A percentage higher than $100 \%$ means that there were other factors whose evolutions in time contributed negatively to the inequalities of the corresponding mobility indicator.

Second, the evolution of inequality in per capita income distribution played a very important role in the evolution of inequalities in mobility on foot and on public transit. For example, it was responsible for $85 \%$ of the reduction of inequalities in trip frequency by public transit (Appendix 28) and for 104\% of the reduction of inequalities in the travel distance (all motorized modes) during the same period (Appendix 29). Apart from that, it was responsible for $105 \%$ of the increase of inequalities in trip frequency on foot (Appendix 28).

During the following period (1991-1997), it was discovered that the role of the evolution of per capita income distribution inequality decreased significantly. Noticeably this evolution contributed negatively to changes in the inequality of many mobility indicators: on the one hand, it counterbalanced the reduction of inequalities in particular as regards those of travelled distance of all motorized modes, by car and trip frequency by public transport but, on the other hand, it offset the rising inequality in the average speed distribution of all motorized modes and car.

Inequality in the distribution of car ownership continued to play an important role in the evolution of inequality in mobility. The dynamic variations of this factor were responsible for reduction of inequalities for the number of trips of all modes, in public transport and on foot and the travelled distance in public transport. In addition, it contributed significantly to the rising inequality of the average speed of all motorized modes and car.

The evolution of the inequality in the distribution of different socio-professional categories contributed to reducing inequalities in the number of trips and distance by car. But it counteracted the reduction of inequalities in the distance and trip frequency by public transport.

The evolution of the inequality in the distribution of age contributed significantly to reducing inequalities in the total distance of travel (all motorized modes) and to offset the rising inequality in the trip frequency on foot.

Finally, the evolution of the inequality in residential location distribution, unlike the previous period, was in most cases, consistent with the overall trends in inequalities of mobility. In other words, changes in the distribution of people living in three areas (Intramural Paris, Inner and Outer Circles) between 1991 and 1997, generally contributed to reducing inequalities of mobility.

As in the previous discussion on the static contribution, there is found a problem that concerns the residuals. High residual values are found in some mobility indicators such as trip frequency per day on foot (1991-1997), travelled distance per day by public transit (1991-1997), and the average travel speed by 
public transit (both periods). Other dependent variables are needed to explain the concentration index evolution of those mobility variables.

Although the analysis of the total variation of the factors contributing to the dynamics of the concentration index is interesting, it does not itself differentiate changes due to the effects of elasticities and inequalities.

Concerning income per capita, we found that the effect of elasticities determined the contribution of this factor to the equalities of mobility indicators. According to the Oaxaca-type decomposition results, this contribution reduced inequality in all indicators, except the average speed for all motorized modes. In other words, instead of rising inequality in per capita income distribution between 1983 and 1991, income factor actually helped reduce inequalities in the travel distance by decreasing the elasticity of trip distance with respect to income. The same was also found in almost all indicators of mobility: neutralizing or reducing the effects of the elasticity of mobility with respect to income appeared to be one of the reasons for the reduction of inequalities in mobility between 1983 and 1991. Exceptions might occur when it comes to the number of walking trips: a decrease in the effects of elasticity contributed to the reduction of the concentration index of the frequency of walking trips which means more concentration of walking trips among low income people and more inequality.

Reductions in the effects of elasticity of mobility compared to the number of cars per capita also contributed in reducing inequalities in mobility, especially in car trips. Neutralizing or reducing the effects of the elasticity of mobility, especially by private car, with respect to the number of cars per capita, appeared to lead to the reduction of inequalities in mobility.

Finally, as raised in the previous section, changes in residential location altogether offset in most cases, changes in inequality. The change in the proportion and distribution of people living in Intramural Paris between 1983 and 1991 contributed in general to increasing inequalities in mobility during the same period. For the Oaxaca method, it is revealed that this increase was due firstly to the increase of the effects of the elasticity of mobility with respect to the fact of living in Intramural Paris between 1983 and 1991.

During the following period, between 1991 and 1997, the overall trend continued. In general, the effect of elasticity was higher than that of inequality. However, in cases of conflict which were somewhat more frequent, sometimes it was the effect of inequality that prevails, especially for the distance travelled by public transport.

\section{Conclusions}

Inequalities in mobility are determined by different socio-economic and geographic factors and income dis- tribution inequality is only one of the important determining factors.

This study found that on any given date, inequality in the distributions of income per capita and car ownership per capita were the two primary factors that help explain most of the inequalities in mobility. Dynamically, the evolution of the inequality of these two factors was also the most important element in reducing inequalities in mobility between 1983 and 1997. The evolution of inequality in the distribution of car ownership during this period greatly affected the evolution of mobility inequality, speed and mobility by private car in particular, while evolution in the inequality of per capita income distribution during the same period determined the evolution of inequality in mobility on foot or by public transport in particular. During the following period (1991 - 1997), the role of the evolution of inequality in the per capita income distribution decreased while that of the per capita car ownership remained important.

It was also noticeable that the contribution of the evolution of determining factors to the evolution of inequality in mobility was driven mostly by the evolution of the effects of cross-elasticities of the indicators of mobility with respect to their determinants. This was especially true for income and car ownership. Between two dates, reducing the effects of cross-elasticities of mobility with respect to income and/or the rate of car ownership seemed to be a means for lowering the concentration indices of mobility and reducing inequality. Lowering the effects of the cross-elasticities can be done, for example, by reducing the regression coefficient of the different mobility indicators with regard to their determining factors, namely income and car ownership. In the real world, policies such as subsidizing public transport tickets with regard to the different income or socio-professional groups should lead to reducing mobility inequality directly and also that of spatial segregation, such as the socio-spatial exclusion phenomenon, indirectly.

The method of decomposition of inequality developed by Oaxaca (1973) and Wagstaff et al. (2003) is valid to decompose the causes of inequality of an object or a variable that is normally distributed or can be expressed by explanatory variables through a model of ordinary least square (OLS). The indicator of mobility as the frequency of travel, or indicator of car ownership level as the number of cars in a household is distributed following multinomial law. A modification of the model of decomposition of inequality for variables whose distributions are abnormal is a subject for future research. This change will allow a better understanding of the contribution of each explanatory variable whose distribution is abnormal.

The use of a better data source is also a point of improvement. The information recorded in the Global Survey of Transport (EGT) is the description of mobility on 
one particular weekday. The reliability can be expected from its sample size: the number of households, individuals, and trips being recorded. However, it might not be a stable representation of mobility behaviour, because mobility can vary from one day to another, from one week to another and from one season to another during the same year. The use of averaged information over a longer time period might improve this aspect.

Finally, there is a difficulty that can be quite disturbing in implementing this approach with regard to the level of mobility itself. Firstly, mobility can be considered as a dependent variable, determined by factors such as income. However, mobility can also be considered as one of the explanatory variables that affects income. In fact the two-way-relationships are valid but in this paper, only the first one has been given attention. Furthermore, this study has presented a set of mobility indicators as dependent variables which have been explained by the same independent variables. The low determination coefficients and the high residual values for some mobility indicators show the consequence of this choice. Future study focusing on fewer mobility indicators explained by more carefully selected independent variables should give more meaningful results. Despite this drawback, our study has shown the potential of the decomposition method used to analyse mobility inequality.

Secondly, mobility level is ambiguous. It is not easy to determine whether a very low trip frequency is the result of some constraining situation suffered by an individual. It is also difficult to determine whether lowmileage travel means the mobility coercion of an individual. Similarly, it is also difficult to say if high mileage undertaken by an individual signifies constraint or freedom for that individual. It is likely that high mileage is the phenomenon of over-mobility (Gibout and Toupin,(2002)). Indicators of mobility remain fairly trivial for this approach. Paulo (2007) states that it is impossible to elaborate precise quantitative criteria or indicators that allow us to order the mobility situation in terms of inequality but we can at least use the most frequently observed trends in individual practice of mobility as references. While Purwanto (2009) gives some preliminary hints on how to set a framework for these criteria, Jouffe, Caubel, Fol and Motte-Baumvol (2015) indicate that mobility inequalities are often interpreted normatively in terms of "lack" which is simply based on the assumption of lower mobility capacity of the poor in one hand and on the other hand, the domination of the rich in terms of movement. This interpretation, according to them, risks reducing the complexity of the phenomenon.

\section{Acknowledgments}

The author would like to thank Jean-Loup Madre and the Institut français des sciences et technologies des transports, de l'aménagement et des réseaux (IFSTTAR, formerly INRETS), Marne-la-Vallée, France for supervising and hosting the author's research activities as a doctoral candidate between 2000 and 2004 where materials, analysis and findings in this paper are among the obtained results. The author would also like to thank Université Louis Lumière Lyon2, Lyon, France, for financing the author's doctoral study and Transport \& Mobility Leuven, Belgium, for technically and financially supporting the writing of this article.

\section{Conflict of Interests}

The author presented an earlier version of this paper in the International Transport Economic Conference in Minneapolis, June $15^{\text {th }} 2009$ under the title "Decomposing the causes of inequalities of people mobility".

\section{References}

Armoogum, J., \& Madre, J.-L. (1997). Item sampling, weighting and non-response. Paper presented at the International Conference on Transport Survey Quality and Innovation. Grainau, Germany.

Baudelot, C., \& Establet, R. (2000). Avoir trente ans: En 1968 et en 1998. Paris: Seuil

Chauvel, L. (1998). Le destin des générations: Structure sociale et cohortes en France au XXe siècle. Paris: Presses Universitaires de France.

Claisse, G., Diaz Olvera, L., Dille, B., Klein, O., Mignot, D., Paulo, C., Plat, D., Pochet, P., (2000). Inégalités de déplacement et équité sociale revenus, indices, et inégalités d'accès à la VP. Résultats provisoires $d u$ projet IDEES (Rapport Intermédiaire no. 2). Paris, France: Ministère de l'Equipement, des Transport et du Logement.

Direction Régionale et Interdépartementale de l'Équipement et de l'Aménagement. (1983). Enquêtes globales transports. Paris, France: Préfet de la région d'île-de-France.

Direction Régionale et Interdépartementale de l'Équipement et de l'Aménagement. (1991). Enquêtes globales transports. Paris, France: Préfet de la région d'île-de-France.

Direction Régionale et Interdépartementale de l'Équipement et de l'Aménagement. (2001). Enquêtes globales transports. Paris, France: Préfet de la région d'île-de-France.

Fournier, M. (2003). Inégalités: De quoi parle-t-on? Sciences humaines, 136, 22-22.

Institut National de la Statistique et des Études Économiques. (1998). Revenus et patrimoine des ménages (INSEE Synthèse 19). Paris, France: Insee.

Jardin, E. (2003). La disparition des rentiers: Entretien avec Thomas Piketty. Sciences humaines, 136, 34-35.

Jouffe, Y., Caubel, D., Fol, S., \& Motte-Baumvol, B. (2015). Faire face aux inégalités de mobilité (docu- 
ment 708). Cybergeo: European Journal of Geography Espace, Société, Territoire. Retrieved from http://cybergeo.revues.org/26697. doi:10.4000/cybe rgeo. 26697

Lachaud, J.-P. (2003). La dynamique de l'inégalité de la malnutrition des enfants en Afrique. Une analyse comparative fondée sur une décomposition de régression. Bordeaux, France: Centre d'économie du développement, Université Montesquieu-Bordeaux.

Madre, J.-L., \& Purwanto, A. J. (2003). Des quantiles interpolés pour suivre l'évolution des inégalités. Paper presented at the 39th Colloque de l'Association de Science Régionale De Langue Française, École nationale des travaux publics de l'État,Lyon.

McNally, M. G. (2000). The activity-based approach. In D. A. Hensher \& K. J. Button (Eds.), Handbook of transport modelling (pp. 55-73). Oxford, UK: Pergamon.

Oaxaca, R. (1973). Male-female wages differences in urban labour markets. International Economic Review, 14, 693-709.

Paulo, C. (2007). Une mesure des inégalités de mobilité et d'accès au volant. EspacesTemps.net. Retrieved from http://www.espacestemps.net/articles/une-me sure-des-inegalites-de-mobilite-et-acces-au-volant
Piketty, T. (2002). L'économie des inégalités. Paris: Editions La Découverte.

Podder, N. (1993). The disaggregation of the Gini coefficient by factor components and its applications to Australia. Review of Income and Wealth, 39(1), 5161.

Purwanto, A. J. (2009). Which equality for mobility. Paper presented at the BIVEC-GIBET transport research day 2009. Vrij Universiteit Brussel (VUB), Brussels, Belgium.

Richardson, A., \& Loeis, M. (1997). Estimation of missing income in household travel surveys. Proceedings of the $21^{\text {st }}$ Australasian transport research forum. (pp.249-266) Victoria, Australia: ARRB Group Limited.

Gibout, C., \& Toupin, F., (2002). Mobilité subie, déplacements choisis: Le cas de la sur-mobilité en région tourangelle. Research synthesis on mobility and inequality. Tours, France: Agence d'Urbanisme de l'Agglomération de Tours.

Wagstaff, A., Van Doorlaer, E., \& Watanabe. (2003). On decomposing the causes of health sector inequalities with an application to malnutrition inequality in Vietnam. Journal of Econometrics, 112, 207-202.

\section{About the Author}

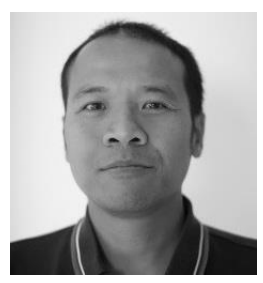

Joko Purwanto obtained his Degree in Civil Engineering in 1997 and is experienced in transport infrastructure project feasibility studies in Indonesia. He pursued Masters (2000) and Doctoral (2004) degrees in transport economics in France. Between 2005 and 2008 he worked as a research fellow in transport and energy sectors modelling at the DG Joint Research Centre of the European Commission in Seville, Spain. In 2008 he joined Transport \& Mobility Leuven in Belgium and works as senior researcher. 
Appendix 1. Incoherencies due to transforming household income class to per capita income decile. Source: 1997 EGT result based calculation*.

\begin{tabular}{|c|c|c|c|c|c|}
\hline Household income class & $\begin{array}{l}\text { Car } \\
\text { ownership } \\
\text { level }\end{array}$ & $\begin{array}{l}\text { Car } \\
\text { ownership } \\
\text { level per } \\
\text { capita }\end{array}$ & $\begin{array}{l}\text { Household income } \\
\text { per capita in } \\
\text { decile }\end{array}$ & $\begin{array}{l}\text { Car } \\
\text { ownership } \\
\text { level }\end{array}$ & $\begin{array}{l}\text { Car } \\
\text { ownership } \\
\text { level per } \\
\text { capita }\end{array}$ \\
\hline Less than $€ 5700$ & 0.21 & 0.18 & D1 (1 $1^{\text {st }}$ decil) & 0,57 & 0,17 \\
\hline$€ 5700-€ 11400$ & 0.27 & 0.17 & D2 & 1,01 & 0,30 \\
\hline$€ 11400-€ 17100$ & 0.43 & 0.26 & D3 & 0,71 & 0,26 \\
\hline$€ 17100-€ 22800$ & 0.74 & 0.40 & D4 & 1,14 & 0,39 \\
\hline$€ 22800-€ 28500$ & 0.92 & 0.46 & D5 & 1,14 & 0,45 \\
\hline$€ 28500-€ 34200$ & 1.17 & 0.50 & D6 & 0,78 & 0,34 \\
\hline$€ 34200-€ 45600$ & 1.27 & 0.51 & D7 & 1,27 & 0,55 \\
\hline$€ 45600-€ 68400$ & 1.54 & 0.58 & D8 & 0,93 & 0,55 \\
\hline$€ 68400-€ 114000$ & 1.64 & 0.59 & D9 & 1,12 & 0,65 \\
\hline More than $€ 114000$ & 1.89 & 0.63 & D10 & 1,03 & 0,67 \\
\hline Average & 0.97 & 0.43 & Average & 0,97 & 0,43 \\
\hline
\end{tabular}

Note: * The original currency used in the data processing was 1998 French Franc. We perform a conversion into $2015 €$ (Euro) to be used as currency in this paper using methodology given by the Institut national de la statistique et des études économiques (Insee) website: http://www.insee.fr/fr/service/reviser/calcul-pouvoir-achat.asp?sommeDepart =1\&deviseDepart=Franc\&anneeDepart=1998\&deviseArrivee=Euro\&anneeArrivee=2015 (as retrieved on 13 May 2016). Given the currency depreciation due to inflation, the purchasing power of 1 (one) French Franc in 1998 is the same as that of 0.19 Euros in 2015.

Appendix 2. Theoretical estimation of household income distribution for each household income class of 1997 EGT. Source: EGT result based calculation.

\begin{tabular}{lll}
\hline Household income class & $\begin{array}{l}\text { Theoretical percentage of household with } \\
\text { income below the class central value }\end{array}$ & $\begin{array}{l}\text { Theoretical percentage of household with } \\
\text { income above the class central value }\end{array}$ \\
\hline Less than $€ 5700$ & Not available (NA*) & NA \\
$€ 5700-€ 11400$ & 0.39 & 0.61 \\
$€ 11400-€ 17100$ & 0.48 & 0.52 \\
$€ 17100-€ 22800$ & 0.51 & 0.49 \\
$€ 22800-€ 28500$ & 0.57 & 0.43 \\
$€ 28500 \mathrm{~F}-€ 34200$ & 0.51 & 0.49 \\
$€ 34200-€ 45600$ & 0.70 & 0.30 \\
$€ 45600-€ 68400$ & 0.81 & 0.19 \\
$€ 68400-€ 114000$ & 0.88 & 0.12 \\
More than $€ 114000$ & $\mathrm{NA}$ & $\mathrm{NA}$ \\
\hline
\end{tabular}

Note: * We need upper and lower values for each class in order to estimate the theoretical percentage. For the lowest and highest class we then assign arbitrary values. 
Appendix 3. Average income in Paris region in 2015 Euros. Source: BDF 1979, 1984, 1989, 1994 results based calculation.

\begin{tabular}{lllll}
\hline & \multicolumn{1}{l}{$\mathbf{1 9 7 9}$} & $\mathbf{1 9 8 4}$ & $\mathbf{1 9 8 9}$ & $\mathbf{1 9 9 4}$ \\
\hline \multirow{2}{*}{ Paris } & \multicolumn{1}{l}{ per-household income } & & \\
Inner Circle & 33693 & 36888 & 38055 & 44699 \\
Outer Circle & 41900 & 37602 & 39715 & 39782 \\
île-de-France & 42434 & 39535 & 40912 & 40320 \\
& 39736 & 38188 & 39704 & 41127 \\
Paris & per-person income & & \\
Inner Circle & 18511 & 20842 & 21569 & 25574 \\
Outer Circle & 17472 & 17332 & 18165 & 18576 \\
île-de-France & 15430 & 15549 & 17383 & 17533 \\
& 17041 & 17485 & 18020 & 20770 \\
Paris & per-consumption unit income & & \\
Inner Circle & 22950 & 25550 & 26324 & 31195 \\
Outer Circle & 24443 & 23247 & 24320 & 24524 \\
île-de-France & 22838 & 22198 & 23857 & 24023 \\
\hline
\end{tabular}

Appendix 4. Average Eurostat scale consumption unit. Source: BDF 1979, 1984, 1989, 1994 results based calculation.

\begin{tabular}{lllll}
\hline & $\mathbf{1 9 7 9}$ & $\mathbf{1 9 8 4}$ & $\mathbf{1 9 8 9}$ & $\mathbf{1 9 9 4}$ \\
\hline Paris & 1.46 & 1.45 & 1.42 & 1.41 \\
Inner Circle & 1.74 & 1.64 & 1.65 & 1.64 \\
Outer Circle & 1.88 & 1.81 & 1.75 & 1.72 \\
Île-de-France & 1.71 & 1.66 & 1.62 & 1.62 \\
\hline
\end{tabular}

Appendix 5. Average income in Paris region in 2015 Euros. Source: calculation results of EGT 1983, 1991, 1997 results based calculation.

\begin{tabular}{llll}
\hline & $\mathbf{1 9 8 3}$ & $\mathbf{1 9 9 1}$ & $\mathbf{1 9 9 7}$ \\
\hline \multirow{2}{*}{ Paris } & per-household income & & \\
Inner Circle & 28613 & 32212 & 31148 \\
Outer Circle & 30438 & 32944 & 31377 \\
Île-de-France & 32298 & 34743 & 34850 \\
& 30576 & 33430 & 32674 \\
Paris & per-person income & & \\
Inner Circle & 17131 & 19326 & 19132 \\
Outer Circle & 14221 & 15833 & 15028 \\
île-de-France & 12928 & 14296 & 14577 \\
\hline
\end{tabular}

Appendix 6. Per household income distribution: Gini coefficients. Source: EGT result based calculation.

\begin{tabular}{lllll}
\hline & Île-de-France & Paris & Inner circle & Outer circle \\
\hline 1983 & 0,30 & 0,34 & 0,29 & 0,28 \\
1991 & 0,35 & 0,40 & 0,34 & 0,32 \\
1997 & 0,36 & 0,40 & 0,33 & 0,35 \\
\hline
\end{tabular}


Appendix 7. Per household income distribution: 10th/1st decile ratios. Source: EGT result based calculation.

\begin{tabular}{lllll}
\hline & île-de-France & Paris & Inner circle & Outer circle \\
\hline 1983 & 8,00 & 10,39 & 7,37 & 6,83 \\
1991 & 11,21 & 17,90 & 9,74 & 9,00 \\
1997 & 11,73 & 17,94 & 9,77 & 10,19 \\
\hline
\end{tabular}

Appendix 8. Per person income distribution: Gini coefficients. Source: EGT result based calculation.

\begin{tabular}{lllll}
\hline & Île-de-France & Paris & Inner circle & Outer circle \\
\hline 1983 & 0,32 & 0,33 & 0,31 & 0,29 \\
1991 & 0,36 & 0,38 & 0,35 & 0,33 \\
1997 & 0,35 & 0,38 & 0,33 & 0,34 \\
\hline
\end{tabular}

Appendix 9. Per person income distribution: 10th /1st decile ratios. Source: EGT result based calculation.

\begin{tabular}{lllll}
\hline & Île-de-France & Paris & Inner circle & Outer circle \\
\hline 1983 & 9,05 & 10,79 & 8,59 & 7,54 \\
1991 & 12,01 & 16,89 & 10,83 & 9,55 \\
1997 & 12,24 & 16,19 & 10,26 & 10,81 \\
\hline
\end{tabular}

Appendix 10. Per household income distribution: Gini coefficients. Source: BDF result based calculation.

\begin{tabular}{lllll}
\hline Year & Île-de-France & Paris & Inner circle & Outer circle \\
\hline 1979 & 0.37 & 0.38 & 0.39 & 0.34 \\
1984 & 0.36 & 0.43 & 0.35 & 0.32 \\
1989 & 0.37 & 0.42 & 0.37 & 0.32 \\
1994 & 0.38 & 0.50 & 0.36 & 0.30 \\
\hline
\end{tabular}

Appendix 11. Per household total income distribution: 10th/1st decile ratios. Source: BDF result based calculation.

\begin{tabular}{lllll}
\hline Year & Île-de-France & Paris & Inner circle & Outer circle \\
\hline 1979 & 13.63 & 14.65 & 13.04 & 11.35 \\
1984 & 13.60 & 23.04 & 13.49 & 9.64 \\
1989 & 13.96 & 16.88 & 15.91 & 9.49 \\
1994 & 14.40 & 50.11 & 11.59 & 7.81 \\
\hline
\end{tabular}

Appendix 12 Per person income distribution: Gini coefficients. Source: BDF result based calculation.

\begin{tabular}{lllll}
\hline Year & île-de-France & Paris & Inner circle & Outer circle \\
\hline 1979 & 0.37 & 0.36 & 0.40 & 0.33 \\
1983 & 0.36 & 0.41 & 0.35 & 0.32 \\
1989 & 0.35 & 0.37 & 0.35 & 0.33 \\
1994 & 0.38 & 0.48 & 0.35 & 0.31 \\
\hline
\end{tabular}

Appendix 13. Per person income distribution: 10th/1st decile ratios. Source: BDF result based calculation.

\begin{tabular}{lllll}
\hline Year & Île-de-France & Paris & Inner circle & Outer circle \\
\hline 1979 & 10.15 & 11.07 & 10.84 & 8.77 \\
1984 & 11.91 & 18.68 & 11.51 & 8.61 \\
1989 & 11.27 & 12.66 & 12.22 & 9.12 \\
1994 & 13.40 & 37.33 & 10.89 & 7.76 \\
\hline
\end{tabular}

Appendix 14. Per consumption unit income distribution: Gini coefficients. Source: BDF result based calculation.

\begin{tabular}{lllll}
\hline Year & Île-de-France & Paris & Inner circle & Outer circle \\
\hline 1979 & 0.34 & 0.34 & 0.38 & 0.31 \\
1983 & 0.33 & 0.39 & 0.32 & 0.29 \\
1989 & 0.33 & 0.36 & 0.33 & 0.29 \\
1994 & 0.35 & 0.47 & 0.33 & 0.27 \\
\hline
\end{tabular}


Appendix 15. Per consumption income unit distribution: 10th/1st decile ratios. Source: BDF result based calculation.

\begin{tabular}{lllll}
\hline Year & île-de-France & Paris & Inner circle & Outer circle \\
\hline 1979 & 9.25 & 10.67 & 9.46 & 7.87 \\
1984 & 10.24 & 17.35 & 10.25 & 7.23 \\
1989 & 9.78 & 11.80 & 10.85 & 7.09 \\
1994 & 10.94 & 36.16 & 8.91 & 6.19 \\
\hline
\end{tabular}

Appendix 16. Per household income distribution: 4th/1st quartile ratios. Source: INSEE Parc Auto result based calculation.

\begin{tabular}{|c|c|c|c|c|c|}
\hline Year & $4^{\text {th }} / 1^{\text {st }}$ & Year & $4^{\text {th }} / 1^{\text {st }}$ & Year & $4^{\text {th }} / 1^{\text {st }}$ \\
\hline 1974 & 5.77 & 1984 & 5.05 & 1994 & 4.91 \\
\hline 1975 & 5.48 & 1985 & 4.50 & 1995 & 5.67 \\
\hline 1976 & 4.90 & 1986 & 4.37 & 1996 & 5.05 \\
\hline 1977 & 5.75 & 1987 & 4.83 & 1997 & 5.71 \\
\hline 1978 & 5.62 & 1988 & 4.63 & 1998 & 5.52 \\
\hline 1979 & 5.42 & 1989 & 4.66 & & \\
\hline 1980 & 5.34 & 1990 & 4.73 & & \\
\hline 1981 & 5.57 & 1991 & 4.56 & & \\
\hline 1982 & 5.65 & 1992 & 4.58 & & \\
\hline 1983 & 4.79 & 1993 & 4.78 & & \\
\hline
\end{tabular}

Appendix 17. Per household income distribution: 4th/1st quartile ratios. Source: BDF result based calculation.

\begin{tabular}{lllll}
\hline Year & île-de-France & Paris & Inner circle & Outer circle \\
\hline 1979 & 5.82 & 6.60 & 5.73 & 5.04 \\
1984 & 5.62 & 7.69 & 5.49 & 4.71 \\
1989 & 5.88 & 7.49 & 6.19 & 4.76 \\
1994 & 6.12 & 12.58 & 5.72 & 4.25 \\
\hline
\end{tabular}

Appendix 18. Distribution (\%) of the different head of family age groups in per consumption unit income classes. Source: BDF 1979, 1984, 1989, 1994 result based calculation.

\begin{tabular}{|c|c|c|c|c|c|c|c|c|}
\hline \multirow[b]{2}{*}{ Age of the head of family } & \multicolumn{2}{|l|}{1979} & \multicolumn{2}{|l|}{1984} & \multicolumn{2}{|l|}{1989} & \multicolumn{2}{|l|}{1994} \\
\hline & $1^{\mathrm{er}}$ & $10^{\text {th }}$ & $1^{\mathrm{er}}$ & $10^{\text {th }}$ & $1^{\mathrm{er}}$ & $10^{\text {th }}$ & $1^{\mathrm{er}}$ & $10^{\text {th }}$ \\
\hline age $<=20$ years & 1.9 & 0.0 & 2.6 & 0.0 & 3.7 & 0.0 & 5.0 & 0.0 \\
\hline $21-25$ years & 7.0 & 1.3 & 7.8 & 1.0 & 10.6 & 0.9 & 17.2 & 0.0 \\
\hline $26-30$ years & 0.9 & 5.7 & 8.9 & 9.7 & 6.9 & 5.7 & 8.1 & 5.0 \\
\hline $31-35$ years & 9.2 & 14.5 & 7.4 & 11.1 & 9.5 & 11.2 & 11.6 & 7.1 \\
\hline $36-40$ years & 6.7 & 10.5 & 8.1 & 11.8 & 10.2 & 9.4 & 7.8 & 7.3 \\
\hline $41-45$ years & 9.4 & 10.8 & 4.3 & 9.6 & 7.1 & 14.3 & 10.5 & 10.5 \\
\hline $46-50$ years & 4.3 & 7.4 & 7.4 & 7.1 & 5.0 & 10.4 & 9.4 & 16.3 \\
\hline $51-55$ years & 5.2 & 16.0 & 5.4 & 14.6 & 7.2 & 11.4 & 8.4 & 11.8 \\
\hline $56-60$ years & 6.7 & 13.0 & 7.1 & 11.0 & 8.4 & 12.7 & 4.7 & 13.7 \\
\hline $61-65$ years & 4.8 & 7.5 & 8.0 & 11.1 & 5.6 & 9.3 & 4.5 & 8.1 \\
\hline 66 years<=age & 44.1 & 13.3 & 33.1 & 12.9 & 25.7 & 14.7 & 12.7 & 20.3 \\
\hline Total & 100.0 & 100.0 & 100.0 & 100.0 & 100.0 & 100.0 & 100.0 & 100.0 \\
\hline
\end{tabular}


Appendix 19. Distribution (\%) of the different socio-professional categories in per consumption unit income classes. Source: BDF result based calculation.

\begin{tabular}{|c|c|c|c|c|c|c|}
\hline \multirow[b]{2}{*}{ Socio-professional category } & \multicolumn{2}{|l|}{1984} & \multicolumn{2}{|l|}{1989} & \multicolumn{2}{|l|}{1994} \\
\hline & $1^{\text {st }}$ & $10^{\text {th }}$ & $1^{\text {st }}$ & $10^{\text {th }}$ & $1^{\text {st }}$ & $10^{\text {th }}$ \\
\hline active: farmers & 1.0 & 0.0 & 0.0 & 0.0 & 0.0 & 0.0 \\
\hline active : craftsmen, retail traders, liberal professions & 5.6 & 3.2 & 8.3 & 6.9 & 5.5 & 8.8 \\
\hline active : executives, liberal professions & 5.9 & 51.1 & 7.7 & 53.9 & 4.9 & 57.6 \\
\hline active : intermediate occupations & 5.8 & 18.7 & 5.6 & 13.0 & 4.4 & 4.1 \\
\hline active : employees & 11.8 & 4.7 & 13.5 & 1.4 & 24.9 & 2.7 \\
\hline active : labourers & 13.6 & 1.4 & 15.3 & 0.9 & 22.2 & 1.2 \\
\hline inactive : retired persons & 37.3 & 19.1 & 23.9 & 23.0 & 14.9 & 23.1 \\
\hline Other inactive & 19.1 & 1.7 & 25.8 & 0.9 & 23.3 & 2.6 \\
\hline Total & 100.0 & 100.0 & 100.0 & 100.0 & 100.0 & 100.0 \\
\hline
\end{tabular}

Appendix 20. Distribution (\%) of the different household types in per consumption unit income classes. Source: BDF result based calculation.

\begin{tabular}{|c|c|c|c|c|c|c|c|c|c|c|c|c|}
\hline \multirow[b]{2}{*}{ Household type } & \multicolumn{3}{|c|}{1979} & \multicolumn{3}{|c|}{1984} & \multicolumn{3}{|c|}{1989} & \multicolumn{3}{|l|}{1994} \\
\hline & $1^{\text {st }}$ & $10^{\text {th }}$ & all & $1^{\text {st }}$ & $10^{\text {th }}$ & all & $1^{\text {st }}$ & $10^{\text {th }}$ & all & $1^{\text {st }}$ & $10^{\text {th }}$ & all \\
\hline Single person household & 50.3 & 18.3 & 24.5 & 46.7 & 24.3 & 28.0 & 46.0 & 26.2 & 31.2 & 45.5 & 29.2 & 32.2 \\
\hline Mono-parental household & 4.0 & 0.6 & 2.2 & 3.1 & 0.0 & 2.3 & 1.9 & 1.8 & 1.9 & 6.8 & 0.0 & 2.7 \\
\hline Large family household & 6.9 & 2.1 & 4.8 & 6.9 & 2.8 & 4.6 & 3.9 & 1.5 & 3.4 & 6.3 & 3.1 & 4.2 \\
\hline Household with at least one unemployed & 12.0 & 2.6 & 6.7 & 20.0 & 2.6 & 8.0 & 17.8 & 1.5 & 8.2 & 30.4 & 6.2 & 11.0 \\
\hline
\end{tabular}




\section{COGITATIO}

Appendix 21. Estimation results of trip frequencies. Source: EGT result based calculation.

\begin{tabular}{|c|c|c|c|c|c|c|c|c|c|c|c|c|}
\hline & \multicolumn{3}{|c|}{ number of total trips/day } & \multicolumn{3}{|c|}{ number of car trips/day } & \multicolumn{3}{|c|}{ number of transit trips/day } & \multicolumn{3}{|c|}{ number of on foot trips/day } \\
\hline & 1983 & 1991 & 1997 & 1983 & 1991 & 1997 & 1983 & 1991 & 1997 & 1983 & 1991 & 1997 \\
\hline Constant & $3,0 \mathrm{E}+03^{* * *}$ & $3,2 \mathrm{E}+03^{* * *}$ & $3,1 \mathrm{E}+03^{* * *}$ & $9,7 \mathrm{E}-01^{* * *}$ & $1,4 \mathrm{E}+03^{* * *}$ & $1,5 \mathrm{E}+03^{* * *}$ & $-4,0 \mathrm{E}-01^{* * *}$ & $-7,4 \mathrm{E}-01^{* * *}$ & $-5,9 \mathrm{E}-01^{* * *}$ & $2,4 \mathrm{E}+03^{* * *}$ & $2,5 \mathrm{E}+03^{* * *}$ & $2,2 \mathrm{E}+03^{* * *}$ \\
\hline Age & $1,4 \mathrm{E}-02^{* *}$ & $3,5 \mathrm{E}-02^{* * *}$ & $6,1 \mathrm{E}-02^{* * *}$ & $5,0 \mathrm{E}-03^{*}$ & $1,2 \mathrm{E}-02^{* *}$ & $1,8 \mathrm{E}-02^{* *}$ & $2,9 \mathrm{E}-02^{* * *}$ & $5,0 \mathrm{E}-02 * * *$ & $4,7 \mathrm{E}-02^{* * *}$ & $-2,0 \mathrm{E}-02 * * *$ & $-2,8 \mathrm{E}-02 * * *$ & $-4,0 \mathrm{E}-03^{*}$ \\
\hline $\mathrm{Age}^{2}$ & $-4,0 \mathrm{E}-04 * * *$ & $-6,0 \mathrm{E}-04 * * *$ & $-9,0 \mathrm{E}-04 * * *$ & $-1,7 \mathrm{E}-04 * * *$ & $-2,6 \mathrm{E}-04 * * *$ & $-3,1 \mathrm{E}-04 * * *$ & $-3,4 \mathrm{E}-04 * * *$ & $-5,5 \mathrm{E}-04 * * *$ & $-5,4 \mathrm{E}-04 * * *$ & $1,1 \mathrm{E}-04 * *$ & $2,1 \mathrm{E}-04 * * *$ & $-5,6 \mathrm{E}-05^{*}$ \\
\hline Income & $4,2 \mathrm{E}-06^{* * *}$ & $8,0 \mathrm{E}-07^{* *}$ & $8,5 \mathrm{E}-07^{*}$ & $-2,3 \mathrm{E}-07^{*}$ & $-3,9 \mathrm{E}-07^{*}$ & $-6,1 \mathrm{E}-07^{*}$ & $3,4 \mathrm{E}-06 * * *$ & $1,5 \mathrm{E}-06^{* * *}$ & $1,8 \mathrm{E}-06^{* * *}$ & $9,9 \mathrm{E}-07^{* *}$ & $-2,8 \mathrm{E}-07^{*}$ & $-3,6 \mathrm{E}-07^{*}$ \\
\hline M-active & $-5,5 \mathrm{E}-02^{*}$ & $-2,3 \mathrm{E}-01^{* * *}$ & $-7,0 \mathrm{E}-01^{* * *}$ & $5,7 \mathrm{E}-01^{* * *}$ & $4,5 \mathrm{E}-01 * * *$ & $-2,5 \mathrm{E}-02 *$ & $4,1 \mathrm{E}-01^{* * *}$ & $4,3 \mathrm{E}-01^{* * *}$ & $3,8 \mathrm{E}-01^{* * *}$ & $-1,0 \mathrm{E}+03^{* * *}$ & $-1,1 \mathrm{E}+03^{* * *}$ & $-1,0 \mathrm{E}+03^{* * *}$ \\
\hline M-retired & $5,1 \mathrm{E}-02^{*}$ & $-6,0 \mathrm{E}-03^{*}$ & $-1,6 \mathrm{E}-01^{*}$ & $-6,5 \mathrm{E}-02 *$ & $-1,5 \mathrm{E}-01^{*}$ & $-2,8 \mathrm{E}-01^{* *}$ & $2,0 \mathrm{E}-01 * * *$ & $2,8 \mathrm{E}-01 * * *$ & $3,2 \mathrm{E}-01^{* * *}$ & $-8,0 \mathrm{E}-02^{*}$ & $-1,4 \mathrm{E}-01^{* *}$ & $-2,0 \mathrm{E}-01^{*}$ \\
\hline M-unemployed & $-2,7 \mathrm{E}-01^{* *}$ & $-4,3 \mathrm{E}-01 * * *$ & $-4,0 \mathrm{E}-01^{* *}$ & $-8,3 \mathrm{E}-02^{*}$ & $-3,4 \mathrm{E}-01 * *$ & $-2,9 \mathrm{E}-01^{*}$ & $3,6 \mathrm{E}-01^{* * *}$ & $3,7 \mathrm{E}-01 * * *$ & $5,1 \mathrm{E}-01^{* * *}$ & $-5,4 \mathrm{E}-01 * * *$ & $-4,6 \mathrm{E}-01 * * *$ & $-6,2 \mathrm{E}-01^{* * *}$ \\
\hline M-student & $-5,8 \mathrm{E}-01^{* * *}$ & $-7,3 \mathrm{E}-01^{* * *}$ & $-7,8 \mathrm{E}-01^{* * *}$ & $-7,3 \mathrm{E}-01^{* * *}$ & $-9,7 \mathrm{E}-01^{* * *}$ & $-9,9 \mathrm{E}-01^{* * *}$ & $5,7 \mathrm{E}-01^{* * *}$ & $9,2 \mathrm{E}-01^{* * *}$ & $5,9 \mathrm{E}-01^{* * *}$ & $-4,2 \mathrm{E}-01^{* * *}$ & $-6,8 \mathrm{E}-01^{* * *}$ & $-3,8 \mathrm{E}-01 * *$ \\
\hline M-at home & $-1,1 \mathrm{E}+03^{* * *}$ & $-1,3 \mathrm{E}+03^{* * *}$ & $-1,4 \mathrm{E}+03^{* * *}$ & $-1,3 \mathrm{E}-01^{*}$ & $-9,3 \mathrm{E}-01^{* *}$ & $-8,6 \mathrm{E}-01 * *$ & $1,4 \mathrm{E}-01 *$ & $7,9 \mathrm{E}-01^{* * *}$ & $5,2 \mathrm{E}-02^{*}$ & $-1,1 \mathrm{E}+03^{* * *}$ & $-1,2 \mathrm{E}+03^{* * *}$ & $-5,7 \mathrm{E}-01 * *$ \\
\hline F-active & $-3,2 \mathrm{E}-02^{*}$ & $-1,5 \mathrm{E}-01 * *$ & $-3,3 \mathrm{E}-01^{* *}$ & $5,0 \mathrm{E}-03^{*}$ & $-4,6 \mathrm{E}-02^{*}$ & $-1,6 \mathrm{E}-01^{*}$ & $6,0 \mathrm{E}-01^{* * *}$ & $6,1 \mathrm{E}-01^{* * *}$ & $5,2 \mathrm{E}-01^{* * *}$ & $-6,4 \mathrm{E}-01^{* * *}$ & $-7,2 \mathrm{E}-01^{* * *}$ & $-6,8 \mathrm{E}-01^{* * *}$ \\
\hline F-retired & $-3,5 \mathrm{E}-01 * * *$ & $-4,3 \mathrm{E}-01^{* * *}$ & $-3,7 \mathrm{E}-01^{* *}$ & $-1,3 \mathrm{E}-01^{*}$ & $-3,8 \mathrm{E}-01 * * *$ & $-5,0 \mathrm{E}-01^{* * *}$ & $9,9 \mathrm{E}-02^{* *}$ & $2,9 \mathrm{E}-01^{* * *}$ & $3,0 \mathrm{E}-01^{* * *}$ & $-3,2 \mathrm{E}-01^{* * *}$ & $-3,4 \mathrm{E}-01^{* * *}$ & $-1,7 \mathrm{E}-01^{*}$ \\
\hline F-unemployed & $-2,6 \mathrm{E}-01^{* *}$ & $-2,5 \mathrm{E}-01^{* *}$ & $-2,5 \mathrm{E}-01^{*}$ & $-2,9 \mathrm{E}-01^{* *}$ & $-4,9 \mathrm{E}-01^{* * *}$ & $-2,3 \mathrm{E}-01^{*}$ & $3,9 \mathrm{E}-01^{* * *}$ & $4,2 \mathrm{E}-01^{* * *}$ & $2,9 \mathrm{E}-01^{* *}$ & $-3,6 \mathrm{E}-01^{* *}$ & $-1,7 \mathrm{E}-01^{* *}$ & $-3,1 \mathrm{E}-01^{* *}$ \\
\hline F-student & $-5,3 \mathrm{E}-01^{* * *}$ & $-5,5 \mathrm{E}-01^{* * *}$ & $-8,0 \mathrm{E}-01^{* * *}$ & $-6,9 \mathrm{E}-01^{* * *}$ & $-9,4 \mathrm{E}-01^{* * *}$ & $-1,0 \mathrm{E}+03^{* * *}$ & $5,4 \mathrm{E}-01^{* * *}$ & $9,9 \mathrm{E}-01^{* * *}$ & $7,1 \mathrm{E}-01^{* * *}$ & $-3,8 \mathrm{E}-01^{* * *}$ & $-6,0 \mathrm{E}-01^{* * *}$ & $-4,8 \mathrm{E}-01^{* * *}$ \\
\hline F-at home & \multicolumn{12}{|c|}{ Category of reference } \\
\hline Paris & $4,23 \mathrm{E}-01^{* * *}$ & $3,14 \mathrm{E}-01^{* * *}$ & $3,23 \mathrm{E}-01 * * *$ & $-6,79 \mathrm{E}-01^{* * *}$ & $-8,98 \mathrm{E}-01 * * *$ & $-9,88 \mathrm{E}-01^{* * *}$ & $5,26 \mathrm{E}-01^{* * *}$ & $5,29 \mathrm{E}-01 * * *$ & $6,08 \mathrm{E}-01^{* * *}$ & $5,76 \mathrm{E}-01 * * *$ & $6,83 \mathrm{E}-01 * * *$ & $7,03 \mathrm{E}-01^{* * *}$ \\
\hline Inner circle & $1,39 \mathrm{E}-01^{* * *}$ & $-4,70 \mathrm{E}-02^{*}$ & $1,17 \mathrm{E}-01^{* *}$ & $-3,43 \mathrm{E}-01^{* * *}$ & $-4,81 \mathrm{E}-01^{* * *}$ & $-3,18 \mathrm{E}-01^{* * *}$ & $2,21 \mathrm{E}-01^{* * *}$ & $1,47 \mathrm{E}-01 * * *$ & $2,31 \mathrm{E}-01^{* * *}$ & $2,60 \mathrm{E}-01 * * *$ & $2,87 \mathrm{E}-01^{* * *}$ & $2,04 \mathrm{E}-01^{* * *}$ \\
\hline Outer circle & \multicolumn{12}{|c|}{ Category of reference } \\
\hline Car ownership & $3,86 \mathrm{E}-01^{* * *}$ & $4,17 \mathrm{E}-01^{* * *}$ & $2,46 \mathrm{E}-01^{* *}$ & $1,94 \mathrm{E}+03^{* * *}$ & $1,75 \mathrm{E}+03^{* * *}$ & $1,80 \mathrm{E}+03^{* * *}$ & $-7,44 \mathrm{E}-01^{* * *}$ & $-6,73 \mathrm{E}-01^{* * *}$ & $-8,00 \mathrm{E}-01^{* * *}$ & $-8,04 \mathrm{E}-01^{* * *}$ & $-6,61 \mathrm{E}-01^{* * *}$ & $-7,54 \mathrm{E}-01^{* * *}$ \\
\hline
\end{tabular}

Note: $t$-student statistics ${ }^{* * *} p<0,0001{ }^{* *} 0,0001<=p<0,05 * p>=0,05$ 
Appendix 22. Estimation result of travel speed. Source: EGT result based calculation.

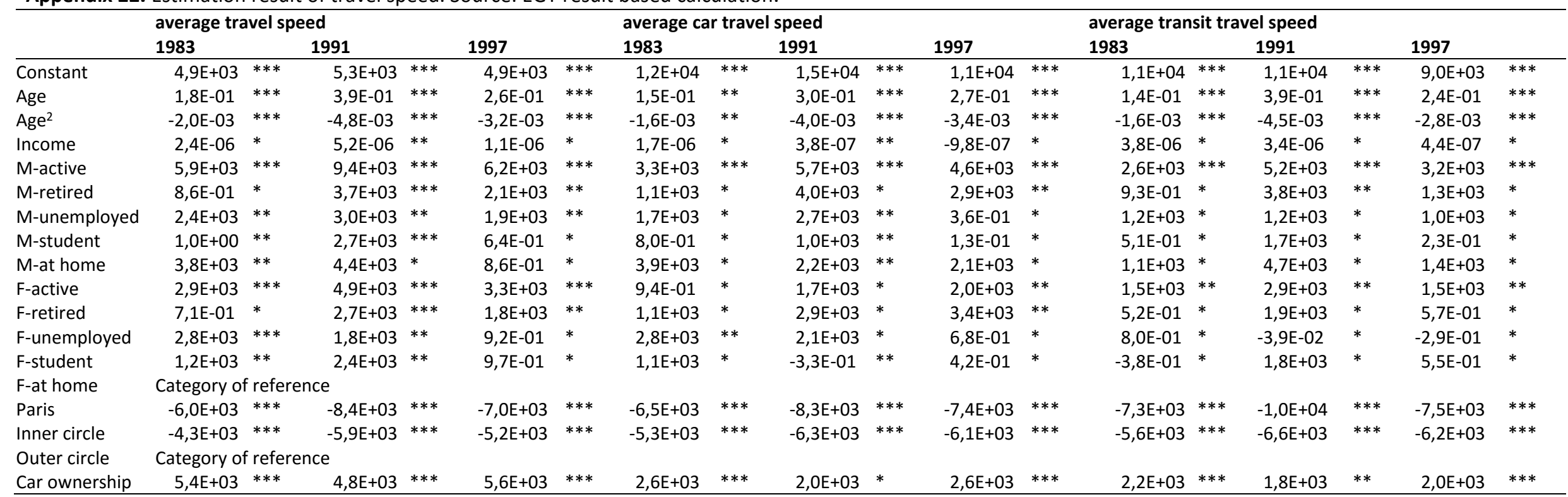

Note: $t$-student statistics $* * * p<0,0001 * * 0,0001<=p<0,05 * p>=0,05$. 
Appendix 23. Estimation results of travel distance. Source: EGT result based calculation.

\begin{tabular}{|c|c|c|c|c|c|c|c|c|c|c|c|c|}
\hline \multicolumn{7}{|c|}{ total km/day } & \multicolumn{6}{|c|}{ total transit km/day } \\
\hline & \multicolumn{2}{|c|}{1983} & \multicolumn{2}{|l|}{1991} & \multicolumn{2}{|l|}{1997} & \multicolumn{2}{|c|}{1983} & \multicolumn{2}{|l|}{1991} & \multicolumn{2}{|l|}{1997} \\
\hline Constant & $6,1 \mathrm{E}-01$ & * & $-4,5 E+03$ & $* *$ & $-1,1 \mathrm{E}+03$ & $*$ & $-1,8 \mathrm{E}+03$ & $*$ & $-8,5 E+03$ & $* *$ & $-4,3 E+03$ & $*$ \\
\hline Age & $3,4 \mathrm{E}-01$ & $* * *$ & $9,3 \mathrm{E}-01$ & $* * *$ & $6,4 \mathrm{E}-01$ & $* * *$ & $2,4 \mathrm{E}-01$ & $* * *$ & 7,2E-01 & $* * *$ & 4,4E-01 & $* *$ \\
\hline $\mathrm{Age}^{2}$ & $-4,1 E-03$ & $* * *$ & $-1,1 \mathrm{E}-02$ & $* * *$ & $-7,5 \mathrm{E}-03$ & $* * *$ & $-2,7 \mathrm{E}-03$ & $* * *$ & $-7,8 \mathrm{E}-03$ & $* * *$ & $-4,8 \mathrm{E}-03$ & $* * *$ \\
\hline Income & 3,3E-05 & $* * *$ & 2,3E-05 & $* * *$ & 2,1E-05 & $* * *$ & 2,7E-05 & $* *$ & 2,1E-05 & $*$ & 1,6E-05 & $*$ \\
\hline M-active & $1,3 E+04$ & $* * *$ & $2,2 E+04$ & $* * *$ & $1,4 \mathrm{E}+04$ & $* * *$ & $5,5 \mathrm{E}+03$ & $* * *$ & $9,3 E+03$ & $* * *$ & $6,3 E+03$ & $* * *$ \\
\hline M-retired & $2,2 \mathrm{E}+03$ & $* *$ & $6,0 E+03$ & $* * *$ & $3,8 \mathrm{E}+03$ & $* *$ & $1,8 \mathrm{E}+03$ & $*$ & $4,0 E+03$ & $* *$ & $2,5 E+03$ & $*$ \\
\hline M-unemployed & $5,5 E+03$ & $* * *$ & $8,4 \mathrm{E}+03$ & $* * *$ & $7,4 E+03$ & $* * *$ & $3,7 \mathrm{E}+03$ & $* *$ & $5,7 E+03$ & $* *$ & $4,7 E+03$ & $* *$ \\
\hline M-student & $3,0 \mathrm{E}+03$ & $* * *$ & $9,3 E+03$ & $* * *$ & $3,3 E+03$ & $* *$ & $4,4 E+03$ & $* *$ & $1,2 \mathrm{E}+04$ & $* *$ & $5,5 E+03$ & $* *$ \\
\hline M-at home & $3,2 E+03$ & $*$ & $8,1 E+03$ & $* *$ & $1,5 E+03$ & $*$ & $1,8 \mathrm{E}+03$ & $*$ & $1,0 \mathrm{E}+04$ & $*$ & $1,6 E+03$ & $*$ \\
\hline F-active & $7,0 E+03$ & $* * *$ & $1,2 E+04$ & $* * *$ & $8,4 \mathrm{E}+03$ & $* * *$ & $6,0 E+03$ & $* *$ & $1,0 E+04$ & $* * *$ & $6,4 \mathrm{E}+03$ & $* *$ \\
\hline F-retired & $1,8 \mathrm{E}+03$ & $* *$ & $4,6 E+03$ & $* * *$ & $3,0 E+03$ & $* *$ & $1,3 \mathrm{E}+03$ & $*$ & $3,7 \mathrm{E}+03$ & $*$ & $2,4 \mathrm{E}+03$ & $*$ \\
\hline $\begin{array}{l}\text { F- } \\
\text { unemployed }\end{array}$ & $3,9 E+03$ & $* *$ & $4,1 E+03$ & $* *$ & $3,1 E+03$ & $* *$ & $2,9 \mathrm{E}+03$ & $*$ & $4,5 E+03$ & $*$ & $2,2 \mathrm{E}+03$ & $*$ \\
\hline F-student & $2,9 E+03$ & $* * *$ & $9,9 E+03$ & $* * *$ & $4,8 E+03$ & $* * *$ & $4,0 E+03$ & $* *$ & $1,2 E+04$ & $* *$ & $6,9 E+03$ & $*$ \\
\hline F-at home & Category & of ref & ence & & & & & & & & & \\
\hline Paris & $-7,0 E+03$ & $* * *$ & $-1,1 E+04$ & $* * *$ & $-1,0 E+04$ & $* * *$ & $-2,2 E+03$ & $* * *$ & $-3,9 E+03$ & $* * *$ & $-2,7 \mathrm{E}+03$ & $* * *$ \\
\hline Inner circle & $-5,1 E+03$ & $* * *$ & $-8,4 \mathrm{E}+03$ & $* * *$ & $-6,9 E+03$ & $* * *$ & $-1,5 E+03$ & $* * *$ & $-2,9 E+03$ & $* * *$ & $-2,2 E+03$ & $* * *$ \\
\hline Outer circle & Category & of ref & ence & & & & & & & & & \\
\hline $\begin{array}{l}\text { Car } \\
\text { ownership }\end{array}$ & $5,6 \mathrm{E}+03$ & $* * *$ & $5,2 \mathrm{E}+03$ & $* * *$ & $4,5 \mathrm{E}+03$ & $* * *$ & $-5,1 E+03$ & $* * *$ & $-8,2 E+03$ & $* * *$ & $-6,8 \mathrm{E}+03$ & $* * *$ \\
\hline
\end{tabular}

Note: $t$-student statistics $* * * p<0,0001 * * 0,0001<=p<0,05 * p>=0,05$.

Appendix 24. Concentration index of mobility indicators in comparison to income per person distribution. Source: EGT result based calculation.

\begin{tabular}{lrrr}
\hline Indicators of mobility & 1983 & 1991 & 1997 \\
\hline Number of trips per day per person (all modes) & 0.035 & 0.020 & 0.005 \\
Number of trips by car per day per person & 0.126 & 0.111 & 0.097 \\
Number of trips by public transit per day per person & 0.093 & 0.028 & 0.008 \\
Number of trips by foot per day per person & -0.079 & -0.100 & -0.110 \\
Distance travelled $(\mathrm{km})$ per day per person (all modes) & 0.125 & 0.096 & 0.092 \\
Distance travelled $(\mathrm{km})$ by car per day per person & 0.168 & 0.155 & 0.155 \\
Distance travelled $(\mathrm{km})$ by public transit per day per person & 0.102 & 0.041 & 0.013 \\
Average speed $(\mathrm{km} / \mathrm{h})$ per day per person (all modes) & 0.090 & 0.066 & 0.077 \\
Average speed $(\mathrm{km} / \mathrm{h})$ by car per day per person & 0.119 & 0.109 & 0.115 \\
Average speed $(\mathrm{km} / \mathrm{h})$ by public transit per day per person & 0.111 & 0.041 & 0.032 \\
\hline
\end{tabular}


Appendix 25. Static contribution of factors to the concentration index of trip frequency per day. Source: EGT result based calculation.

\begin{tabular}{lllllllllllll}
\hline Variable & \multicolumn{1}{l}{ All modes } & \multicolumn{4}{c}{ Private car } & \multicolumn{4}{c}{ Public transit } & \multicolumn{3}{c}{ On foot } \\
& $\mathbf{1 9 8 3}$ & $\mathbf{1 9 9 1}$ & $\mathbf{1 9 9 7}$ & $\mathbf{1 9 8 3}$ & $\mathbf{1 9 9 1}$ & $\mathbf{1 9 9 7}$ & $\mathbf{1 9 8 3}$ & $\mathbf{1 9 9 1}$ & $\mathbf{1 9 9 7}$ & $\mathbf{1 9 8 3}$ & $\mathbf{1 9 9 1}$ & $\mathbf{1 9 9 7}$ \\
\hline Age & $31 \%$ & $145 \%$ & $1269 \%$ & $8 \%$ & $21 \%$ & $43 \%$ & $129 \%$ & $714 \%$ & $3600 \%$ & $51 \%$ & $66 \%$ & $11 \%$ \\
Age2 & $-66 \%$ & $-185 \%$ & $-1481 \%$ & $-20 \%$ & $-32 \%$ & $-60 \%$ & $-105 \%$ & $-571 \%$ & $-3333 \%$ & $-19 \%$ & $-37 \%$ & $12 \%$ \\
Income & $\mathbf{2 7 \%}$ & $31 \%$ & $123 \%$ & $-3 \%$ & $-6 \%$ & $-10 \%$ & $118 \%$ & $196 \%$ & $987 \%$ & $-20 \%$ & $6 \%$ & $7 \%$ \\
M-active & $-1 \%$ & $-10 \%$ & $-115 \%$ & $11 \%$ & $8 \%$ & $0 \%$ & $22 \%$ & $68 \%$ & $240 \%$ & $30 \%$ & $28 \%$ & $23 \%$ \\
M-retired & $0 \%$ & $0 \%$ & $-14 \%$ & $0 \%$ & $-1 \%$ & $-3 \%$ & $2 \%$ & $13 \%$ & $109 \%$ & $0 \%$ & $1 \%$ & $2 \%$ \\
M-unemployed & $2 \%$ & $4 \%$ & $23 \%$ & $0 \%$ & $1 \%$ & $2 \%$ & $-5 \%$ & $-12 \%$ & $-115 \%$ & $-4 \%$ & $-3 \%$ & $-5 \%$ \\
M-student & $16 \%$ & $33 \%$ & $148 \%$ & $14 \%$ & $18 \%$ & $22 \%$ & $-30 \%$ & $-146 \%$ & $-413 \%$ & $-13 \%$ & $-18 \%$ & $-9 \%$ \\
M-at home & $0 \%$ & $0 \%$ & $7 \%$ & $0 \%$ & $0 \%$ & $0 \%$ & $0 \%$ & $0 \%$ & $-1 \%$ & $0 \%$ & $0 \%$ & $0 \%$ \\
F-active & $-1 \%$ & $-8 \%$ & $-62 \%$ & $0 \%$ & $-1 \%$ & $-4 \%$ & $39 \%$ & $111 \%$ & $360 \%$ & $23 \%$ & $22 \%$ & $17 \%$ \\
F-retired & $-3 \%$ & $-7 \%$ & $-38 \%$ & $-1 \%$ & $-2 \%$ & $-6 \%$ & $1 \%$ & $16 \%$ & $117 \%$ & $3 \%$ & $3 \%$ & $2 \%$ \\
F-unemployed & $1 \%$ & $2 \%$ & $12 \%$ & $1 \%$ & $1 \%$ & $1 \%$ & $-3 \%$ & $-10 \%$ & $-52 \%$ & $-2 \%$ & $-1 \%$ & $-2 \%$ \\
F-student & $12 \%$ & $25 \%$ & $165 \%$ & $11 \%$ & $17 \%$ & $25 \%$ & $-23 \%$ & $-154 \%$ & $-547 \%$ & $-9 \%$ & $-15 \%$ & $-13 \%$ \\
Paris & $12 \%$ & $13 \%$ & $54 \%$ & $-14 \%$ & $-15 \%$ & $-20 \%$ & $29 \%$ & $75 \%$ & $373 \%$ & $-18 \%$ & $-16 \%$ & $-15 \%$ \\
Inner circle & $-1 \%$ & $0 \%$ & $-6 \%$ & $1 \%$ & $1 \%$ & $2 \%$ & $-2 \%$ & $-3 \%$ & $-45 \%$ & $1 \%$ & $1 \%$ & $1 \%$ \\
Car ownership & $26 \%$ & $55 \%$ & $121 \%$ & $92 \%$ & $90 \%$ & $103 \%$ & $-94 \%$ & $-296 \%$ & $-1467 \%$ & $57 \%$ & $48 \%$ & $48 \%$ \\
Residual & $8 \%$ & $0.5 \%$ & $-98 \%$ & $2 \%$ & $1 \%$ & $3 \%$ & $23 \%$ & $100 \%$ & $200 \%$ & $19 \%$ & $18 \%$ & $23 \%$ \\
Total & $100 \%$ & $100 \%$ & $100 \%$ & $100 \%$ & $100 \%$ & $100 \%$ & $100 \%$ & $100 \%$ & $100 \%$ & $100 \%$ & $100 \%$ & $100 \%$ \\
\hline
\end{tabular}

Appendix 26. Static contribution of factors to the concentration index of travelled distance per day. Source: EGT result based calculation.

\begin{tabular}{|c|c|c|c|c|c|c|c|c|c|}
\hline \multirow[t]{2}{*}{ Variable } & \multicolumn{3}{|c|}{ All modes } & \multicolumn{3}{|c|}{ Private car } & \multicolumn{3}{|c|}{ Public transit } \\
\hline & 1983 & 1991 & 1997 & 1983 & 1991 & 1997 & 1983 & 1991 & 1997 \\
\hline Age & $58 \%$ & $125 \%$ & $163 \%$ & $25 \%$ & $35 \%$ & $51 \%$ & $120 \%$ & $537 \%$ & $2231 \%$ \\
\hline Age2 & $-49 \%$ & $-104 \%$ & $-152 \%$ & $-23 \%$ & $-35 \%$ & $-54 \%$ & $-97 \%$ & $-439 \%$ & $-1923 \%$ \\
\hline Income & $44 \%$ & $29 \%$ & $38 \%$ & $10 \%$ & $3 \%$ & $9 \%$ & $110 \%$ & $146 \%$ & $562 \%$ \\
\hline M-active & $25 \%$ & $32 \%$ & $29 \%$ & $20 \%$ & $24 \%$ & $18 \%$ & $32 \%$ & $73 \%$ & $254 \%$ \\
\hline M-retired & $1 \%$ & $3 \%$ & $4 \%$ & $0 \%$ & $1 \%$ & $1 \%$ & $2 \%$ & $10 \%$ & $55 \%$ \\
\hline M-unemployed & $-3 \%$ & $-3 \%$ & $-6 \%$ & $-1 \%$ & $-1 \%$ & $-2 \%$ & $-6 \%$ & $-10 \%$ & $-68 \%$ \\
\hline M-student & $-6 \%$ & $-14 \%$ & $-8 \%$ & $4 \%$ & $4 \%$ & $5 \%$ & $-26 \%$ & $-95 \%$ & $-254 \%$ \\
\hline M-at home & $0 \%$ & $0 \%$ & $0 \%$ & $0 \%$ & $0 \%$ & $0 \%$ & $0 \%$ & $0 \%$ & $-2 \%$ \\
\hline F-active & $17 \%$ & $21 \%$ & $20 \%$ & $4 \%$ & $5 \%$ & $6 \%$ & $43 \%$ & $95 \%$ & $292 \%$ \\
\hline F-retired & $1 \%$ & $3 \%$ & $4 \%$ & $0 \%$ & $1 \%$ & $1 \%$ & $2 \%$ & $11 \%$ & $61 \%$ \\
\hline F-unemployed & $-1 \%$ & $-1 \%$ & $-2 \%$ & $0 \%$ & $0 \%$ & $-1 \%$ & $-3 \%$ & $-5 \%$ & $-25 \%$ \\
\hline F-student & $-5 \%$ & $-15 \%$ & $-12 \%$ & $3 \%$ & $4 \%$ & $6 \%$ & $-20 \%$ & $-100 \%$ & $-346 \%$ \\
\hline Paris & $-14 \%$ & $-16 \%$ & $-21 \%$ & $-14 \%$ & $-13 \%$ & $-16 \%$ & $-13 \%$ & $-29 \%$ & $-108 \%$ \\
\hline Inner circle & $1 \%$ & $2 \%$ & $5 \%$ & $1 \%$ & $1 \%$ & $3 \%$ & $1 \%$ & $3 \%$ & $28 \%$ \\
\hline Car ownership & $27 \%$ & $22 \%$ & $27 \%$ & $71 \%$ & $73 \%$ & $73 \%$ & $-73 \%$ & $-188 \%$ & $-769 \%$ \\
\hline Residual & $8 \%$ & $17 \%$ & $8 \%$ & $-3 \%$ & $3 \%$ & $2 \%$ & $32 \%$ & $78 \%$ & $147 \%$ \\
\hline Total & $100 \%$ & $100 \%$ & $100 \%$ & $100 \%$ & $100 \%$ & $100 \%$ & $100 \%$ & $100 \%$ & $100 \%$ \\
\hline
\end{tabular}


Appendix 27. Static contribution of factors to the concentration index of the average travel speed. Source: EGT result based calculation.

\begin{tabular}{llllllllll}
\hline Variable & \multicolumn{2}{l}{ All modes } & \multicolumn{3}{c}{ Private car } & \multicolumn{4}{c}{ Public transit } \\
& $\mathbf{1 9 8 3}$ & $\mathbf{1 9 9 1}$ & $\mathbf{1 9 9 7}$ & $\mathbf{1 9 8 3}$ & $\mathbf{1 9 9 1}$ & $\mathbf{1 9 9 7}$ & $\mathbf{1 9 8 3}$ & $\mathbf{1 9 9 1}$ & $\mathbf{1 9 9 7}$ \\
\hline Age & $52 \%$ & $115 \%$ & $116 \%$ & $22 \%$ & $37 \%$ & $55 \%$ & $30 \%$ & $163 \%$ & $269 \%$ \\
Age2 & $-42 \%$ & $-105 \%$ & $-109 \%$ & $-16 \%$ & $-37 \%$ & $-55 \%$ & $-25 \%$ & $-139 \%$ & $-244 \%$ \\
Income & $6 \%$ & $14 \%$ & $3 \%$ & $2 \%$ & $0 \%$ & $-1 \%$ & $7 \%$ & $13 \%$ & $3 \%$ \\
M-active & $20 \%$ & $29 \%$ & $22 \%$ & $5 \%$ & $8 \%$ & $7 \%$ & $7 \%$ & $23 \%$ & $28 \%$ \\
M-retired & $1 \%$ & $4 \%$ & $4 \%$ & $0 \%$ & $2 \%$ & $3 \%$ & $0 \%$ & $5 \%$ & $6 \%$ \\
M-unemployed & $-2 \%$ & $-2 \%$ & $-2 \%$ & $-1 \%$ & $-1 \%$ & $0 \%$ & $-1 \%$ & $-1 \%$ & $-3 \%$ \\
M-student & $-4 \%$ & $-9 \%$ & $-3 \%$ & $-1 \%$ & $-1 \%$ & $0 \%$ & $-1 \%$ & $-8 \%$ & $-2 \%$ \\
M-at home & $0 \%$ & $0 \%$ & $0 \%$ & $0 \%$ & $0 \%$ & $0 \%$ & $0 \%$ & $0 \%$ & $0 \%$ \\
F-active & $12 \%$ & $18 \%$ & $13 \%$ & $2 \%$ & $3 \%$ & $4 \%$ & $5 \%$ & $16 \%$ & $14 \%$ \\
F-retired & $1 \%$ & $3 \%$ & $4 \%$ & $1 \%$ & $1 \%$ & $3 \%$ & $0 \%$ & $3 \%$ & $3 \%$ \\
F-unemployed & $-1 \%$ & $-1 \%$ & $-1 \%$ & $-1 \%$ & $0 \%$ & $0 \%$ & $0 \%$ & $0 \%$ & $1 \%$ \\
F-student & $-3 \%$ & $-8 \%$ & $-4 \%$ & $-1 \%$ & $0 \%$ & $-1 \%$ & $1 \%$ & $-8 \%$ & $-6 \%$ \\
Paris & $-21 \%$ & $-24 \%$ & $-25 \%$ & $-11 \%$ & $-10 \%$ & $-12 \%$ & $-20 \%$ & $-41 \%$ & $-66 \%$ \\
Inner circle & $2 \%$ & $3 \%$ & $6 \%$ & $1 \%$ & $1 \%$ & $3 \%$ & $2 \%$ & $4 \%$ & $18 \%$ \\
Car ownership & $44 \%$ & $42 \%$ & $57 \%$ & $11 \%$ & $8 \%$ & $13 \%$ & $14 \%$ & $23 \%$ & $50 \%$ \\
Residual & $36 \%$ & $20 \%$ & $20 \%$ & $83 \%$ & $88 \%$ & $86 \%$ & $82 \%$ & $49 \%$ & $30 \%$ \\
\hline Total & $100 \%$ & $100 \%$ & $100 \%$ & $100 \%$ & $100 \%$ & $100 \%$ & $100 \%$ & $100 \%$ & $100 \%$ \\
\hline
\end{tabular}

Appendix 28. Dynamic contribution of factors to the concentration index of trip frequency per day. Source: EGT result based calculation.

\begin{tabular}{|c|c|c|c|c|c|c|c|c|}
\hline & \multicolumn{2}{|c|}{ All modes } & \multicolumn{2}{|c|}{ Private cars } & \multicolumn{2}{|c|}{ Public transit } & \multicolumn{2}{|l|}{ On foot } \\
\hline & $\begin{array}{l}1983- \\
1991\end{array}$ & $\begin{array}{l}1991- \\
1997\end{array}$ & $\begin{array}{l}1983- \\
1991\end{array}$ & $\begin{array}{l}1991- \\
1997\end{array}$ & $\begin{array}{l}1983- \\
1991\end{array}$ & $\begin{array}{l}1991- \\
1997\end{array}$ & $\begin{array}{l}1983- \\
1991\end{array}$ & $\begin{array}{l}1991- \\
1997\end{array}$ \\
\hline Age & $-120,0 \%$ & $-250,0 \%$ & $-60,0 \%$ & $-146,2 \%$ & $-123,1 \%$ & $-341,5 \%$ & $123,8 \%$ & $-540,0 \%$ \\
\hline Age2 & $93,3 \%$ & $270,3 \%$ & $45,0 \%$ & $176,9 \%$ & $95,4 \%$ & $439,0 \%$ & $-104,8 \%$ & $500,0 \%$ \\
\hline Income & $138,7 \%$ & $-1,4 \%$ & $13,5 \%$ & $25,4 \%$ & $84,6 \%$ & $-92,7 \%$ & $105,7 \%$ & $14,0 \%$ \\
\hline M-active & $9,9 \%$ & $27,0 \%$ & $26,5 \%$ & $70,6 \%$ & $1,5 \%$ & $4,9 \%$ & $19,0 \%$ & $-30,0 \%$ \\
\hline M-retired & $0,8 \%$ & $5,0 \%$ & $2,8 \%$ & $15,6 \%$ & $-2,8 \%$ & $-22,0 \%$ & $3,4 \%$ & $15,0 \%$ \\
\hline M-unemployed & $-0,9 \%$ & $-2,6 \%$ & $-4,4 \%$ & $-4,6 \%$ & $-1,5 \%$ & $25,4 \%$ & $3,8 \%$ & $-28,0 \%$ \\
\hline M-student & $-6,0 \%$ & $-7,4 \%$ & $-10,0 \%$ & $-7,7 \%$ & $20,0 \%$ & $-48,8 \%$ & $-38,1 \%$ & $80,0 \%$ \\
\hline M-at home & $0,0 \%$ & $-2,4 \%$ & $0,0 \%$ & $-3,7 \%$ & $0,0 \%$ & $0,3 \%$ & $0,0 \%$ & $-4,0 \%$ \\
\hline F-active & $8,1 \%$ & $10,8 \%$ & $6,3 \%$ & $17,7 \%$ & $7,7 \%$ & $19,5 \%$ & $19,0 \%$ & $-30,0 \%$ \\
\hline F-retired & $3,3 \%$ & $4,1 \%$ & $9,1 \%$ & $25,4 \%$ & $-4,8 \%$ & $-21,5 \%$ & $5,2 \%$ & $-5,0 \%$ \\
\hline F-unemployed & $0,4 \%$ & $-2,0 \%$ & $-1,5 \%$ & $0,8 \%$ & $-0,2 \%$ & $5,9 \%$ & $2,6 \%$ & $-14,5 \%$ \\
\hline F-student & $-4,7 \%$ & $-25,0 \%$ & $-25,0 \%$ & $-38,5 \%$ & $33,8 \%$ & $-9,8 \%$ & $-36,7 \%$ & $10,0 \%$ \\
\hline Paris & $11,3 \%$ & $-1,4 \%$ & $-5,0 \%$ & $15,4 \%$ & $9,2 \%$ & $-34,1 \%$ & $-9,5 \%$ & $-10,0 \%$ \\
\hline Inner circle & $-1,6 \%$ & $2,6 \%$ & $-1,5 \%$ & $-3,8 \%$ & $-0,8 \%$ & $12,1 \%$ & $1,0 \%$ & $6,0 \%$ \\
\hline Car ownership & $-13,3 \%$ & $31,8 \%$ & $105,0 \%$ & $-7,7 \%$ & $-6,2 \%$ & $131,7 \%$ & $14,3 \%$ & $50,0 \%$ \\
\hline Residual & $-19,2 \%$ & $40,7 \%$ & $-0,7 \%$ & $-35,6 \%$ & $-13,1 \%$ & $31,4 \%$ & $-8,9 \%$ & $86,5 \%$ \\
\hline Total & $100,0 \%$ & $100,0 \%$ & $100,0 \%$ & $100,0 \%$ & $100,0 \%$ & $100,0 \%$ & $100,0 \%$ & $100,0 \%$ \\
\hline
\end{tabular}


Appendix 29. Dynamic contribution of factors to the concentration index of travelled distance per day. Source: EGT result based calculation.

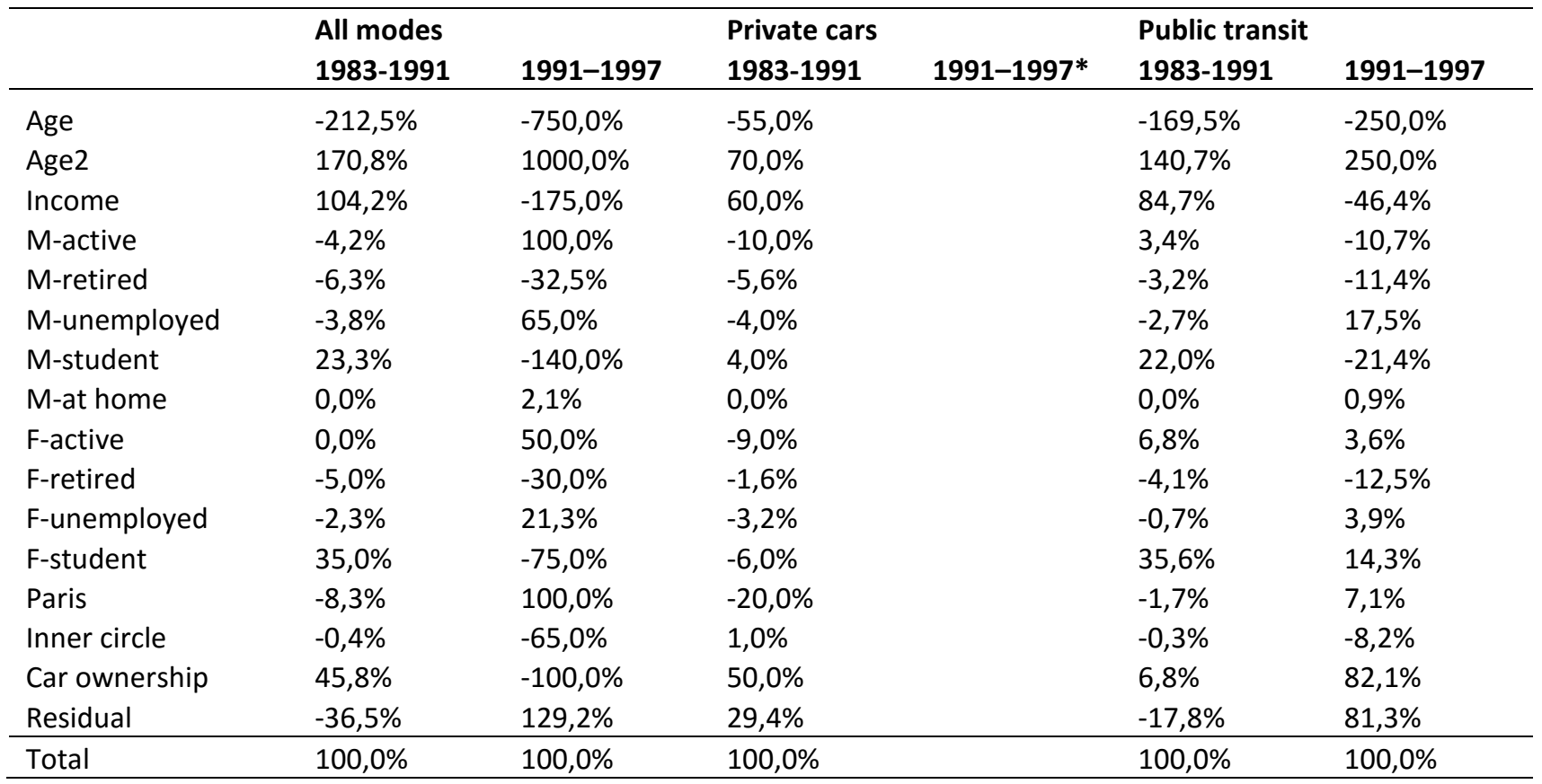

Note: * concentration index of the corresponding variable does not change during this period.

Appendix 30. Dynamic contribution of factors to the concentration index of the average travel speed. Source: EGT result based calculation.

\begin{tabular}{|c|c|c|c|c|c|c|}
\hline & \multicolumn{2}{|l|}{ All modes } & \multicolumn{2}{|l|}{ Private cars } & \multicolumn{2}{|c|}{ Public transit } \\
\hline & 1983-1991 & 1991-1997 & 1983-1991 & 1991-1997* & 1983-1991 & 1991-1997 \\
\hline Age & $-120,8 \%$ & $118,2 \%$ & $-150,0 \%$ & & $-49,3 \%$ & $-211,1 \%$ \\
\hline Age2 & $129,2 \%$ & $-136,4 \%$ & $220,0 \%$ & & $42,0 \%$ & $233,3 \%$ \\
\hline Income & $-18,3 \%$ & $-63,6 \%$ & $17,1 \%$ & & $3,0 \%$ & $47,8 \%$ \\
\hline M-active & $-4,2 \%$ & $-18,2 \%$ & $-20,0 \%$ & & $-2,9 \%$ & $7,8 \%$ \\
\hline M-retired & $-7,8 \%$ & $6,4 \%$ & $-13,6 \%$ & & $-2,4 \%$ & $2,2 \%$ \\
\hline M-unemployed & $-2,5 \%$ & $-5,5 \%$ & $0,0 \%$ & & $-0,6 \%$ & $7,1 \%$ \\
\hline M-student & $10,8 \%$ & $34,5 \%$ & $0,0 \%$ & & $2,6 \%$ & $-28,4 \%$ \\
\hline M-at home & $0,0 \%$ & $-0,6 \%$ & $0,0 \%$ & & $0,0 \%$ & $1,3 \%$ \\
\hline F-active & $-4,2 \%$ & $-18,2 \%$ & $-7,0 \%$ & & $-1,7 \%$ & $20,0 \%$ \\
\hline F-retired & $-5,9 \%$ & $9,1 \%$ & $-8,9 \%$ & & $-1,3 \%$ & $3,4 \%$ \\
\hline F-unemployed & $-3,1 \%$ & $-1,5 \%$ & $-3,7 \%$ & & $-0,5 \%$ & $-2,4 \%$ \\
\hline F-student & $8,3 \%$ & $16,4 \%$ & $-21,8 \%$ & & $6,2 \%$ & $-16,7 \%$ \\
\hline Paris & $-12,5 \%$ & $-27,3 \%$ & $-20,0 \%$ & & $-7,2 \%$ & $44,4 \%$ \\
\hline Inner circle & $0,4 \%$ & $25,5 \%$ & $1,0 \%$ & & $0,7 \%$ & $-43,3 \%$ \\
\hline Car ownership & $50,0 \%$ & $145,5 \%$ & $47,0 \%$ & & $8,1 \%$ & $-73,3 \%$ \\
\hline Residual & $80,5 \%$ & $15,7 \%$ & $59,9 \%$ & & $103,2 \%$ & $107,9 \%$ \\
\hline Total & $100,0 \%$ & $100,0 \%$ & $100,0 \%$ & & $100,0 \%$ & $100,0 \%$ \\
\hline
\end{tabular}

Note: * concentration index of the corresponding variable does not change during this period. 